\title{
Terrain-Trapped Airflows and Orographic Rainfall along the Coast of Northern California. Part II: Horizontal and Vertical Structures Observed by a Scanning Doppler Radar
}

\author{
RAul A. VALENZUEla ${ }^{\mathrm{a}}$ \\ Department of Atmospheric and Oceanic Sciences, and Cooperative Institute for Research in Environmental Sciences, \\ University of Colorado Boulder, Boulder, Colorado \\ DAVID E. KINGSMILL \\ Cooperative Institute for Research in Environmental Sciences, University of Colorado Boulder, Boulder, Colorado
}

(Manuscript received 8 August 2017, in final form 15 May 2018)

\begin{abstract}
This study documents the mean properties and variability of kinematic and precipitation structures associated with orographic precipitation along the coast of Northern California in the context of terrain-trapped airflows (TTAs). TTAs are defined as relatively narrow air masses that consistently flow in close proximity and approximately parallel to an orographic barrier. Seven land-falling winter storms are examined with observations from a scanning X-band Doppler radar deployed on the coast at Fort Ross, California. Additional information is provided by a $915-\mathrm{MHz}$ wind-profiling radar, surface meteorology, a GPS receiver, and balloon soundings. The composite kinematic structure during TTA conditions exhibits a significant horizontal gradient of wind direction from the coast to approximately $50 \mathrm{~km}$ offshore and a low-level jet (LLJ) that surmounts a weaker airflow offshore corresponding to the TTA, with a zone of enhanced precipitation evident between $\sim 5$ and $25 \mathrm{~km}$ offshore and oriented nearly parallel to the coastline. Conversely, the composite kinematic structure during NO-TTA conditions exhibits a smaller offshore horizontal gradient of wind direction and precipitation structures are generally enhanced within $\sim 15 \mathrm{~km}$ of the coastline. Interstorm variability analysis reveals significant variations in kinematic structures during both TTA and NO-TTA conditions, whereas significant variations in precipitation structures are only evident during TTA conditions. The interstorm analysis also illustrates more clearly how LLJ vertical structures evident during NO-TTA conditions exhibit ascent along the coast and over the coastal mountains, which is in contrast to TTA conditions where the ascent occurs offshore and over the TTA.
\end{abstract}

\section{Introduction}

Land-falling extratropical cyclones are responsible for the majority of precipitation that falls in the western United States. The spatial distribution of precipitation from these storms is strongly influenced by the regions' complex terrain. A narrow channel of concentrated horizontal water vapor flux in the lowest 3-4 km MSL is often present immediately ahead of the cold fronts associated

\footnotetext{
${ }^{a}$ Current affiliation: Department of Geophysics and Center for Climate and Resilience Research, University of Chile, Santiago, Chile.
}

Corresponding author: Raul A. Valenzuela, raul.valenzuela@ colorado.edu with extratropical cyclones. These atmospheric rivers (ARs; Zhu and Newell 1994; Ralph et al. 2004) are typically collocated with the pre-cold-frontal low-level jet (LLJ). Upon impacting the terrain, ARs can facilitate moist orographic uplift that leads to enhanced precipitation (e.g., Ralph et al. 2005; Neiman et al. 2009).

A significant fraction of orographic precipitation can be explained by this relatively simple upslope flow mechanism. Attempts have been made to describe the upslope flow mechanism with linear models of orographic precipitation (e.g., Smith and Barstad 2004; Smith et al. 2005). While informative, these models are unable to resolve small-scale details of the precipitation distribution on hourly time scales (e.g., Garreaud et al. 2016). Some sources of this limitation are associated with embedded convection (e.g., Kirshbaum and Durran 2004), 
nonlinear microphysical processes (e.g., Stoelinga et al. 2013), and the presence of complex nonlinear interactions between synoptic and mountain-induced airflows. In the latter case, a broad redistribution of precipitation can be observed upstream of the mountain because the impinging moist airflow is forced to ascend before reaching the orographic barrier (e.g., Houze et al. 2001). One of the mountain-induced airflows is known as a terrain-trapped airflow (TTA), which is defined as a relatively narrow air mass consistently flowing in close proximity and approximately parallel to an orographic barrier (Valenzuela and Kingsmill 2015, hereafter VK15).

Orographic precipitation associated with TTAs has generally been studied in the context of large-scale mountains (i.e., altitudes above $\sim 1000$ m MSL; Parish 1982; Marwitz 1983; Peterson et al. 1991; Sinclair et al. 1997; Medina et al. 2005; Yu and Hsieh 2009; Neiman et al. 2010; Kingsmill et al. 2013), whereas research associated with small-scale mountains has received relatively little attention. It is notable that orographic precipitation over small-scale mountains is more likely to produce rapid runoff and floods caused by precipitation of rain (instead of snow) and scarce or nonexistent flood control structures. This is a particularly relevant issue along coastal mountains such as in Northern California, where ARs can directly interact with the coastal terrain to produce intense rainfall that can lead to significant economic impacts (e.g., Ralph et al. 2006).

Neiman et al. (2002, 2006), Yu and Smull (2000), and James and Houze (2005) examined TTA influence on orographic precipitation along the coastal mountains of Northern California. While these studies provided new insights about TTAs and their effects on orographic precipitation associated with small-scale orography, they were limited in a few important respects. The results of Neiman et al. $(2002,2006)$ were derived from wind profiling radar observations and thus were constrained by a one-dimensional, vertical-profile perspective. In contrast, $\mathrm{Yu}$ and Smull (2000) and James and Houze (2005) employed scanning Doppler radar observations, allowing for a three-dimensional context. However, their observations had incomplete documentation of airflows below the peaks of the coastal terrain, which is essential for examination of TTAs. VK15 addressed these limitations by documenting the kinematic and precipitation structures of a coastal-mountain TTA. Although their study provided unprecedented details, it was based on only a single storm. Accordingly, there is uncertainty regarding the generality of their results.

Part I of the present study developed an objective method to identify TTA regimes along the coast of
Northern California using wind-profiling radar and surface meteorology observations collected over 13 winter seasons (Valenzuela and Kingsmill 2017, hereafter Part I; summarized below at the beginning of section 4a). In Part II, a ground-based scanning Doppler radar is used to document the detailed three-dimensional kinematic and precipitation structures of TTAs associated with seven winter storms making landfall along the coast of Northern California. The results from Part I are employed to objectively identify TTA regimes observed in each storm. This study is unique because it characterizes the mean properties and variability of TTA kinematic and precipitation structures that occur in connection with coastal orographic precipitation. Section 2 describes the observing systems and data processing techniques employed in the analysis. An overview of each storm is presented in section 3, while detailed kinematic and precipitation structures associated with TTAs in each storm are described and discussed in section 4. Finally, section 5 presents the summary and conclusions of this study.

\section{Observing systems and data processing}

The description of the observing systems and processing methods utilized in this investigation is largely the same as in VK15. Thus, the following text is derived from VK15 with minor modifications that account for the larger number of storms included in the present study.

Observations employed in this study were collected during the landfall of seven winter storms along the Northern California coast and were part of the Hydrometeorology Testbed experiments (Ralph et al. 2013) operated by the National Oceanic and Atmospheric Administration's (NOAA) Earth System Research Laboratory (ESRL). Locations of key observing systems are shown in Fig. 1 and observation periods are defined in Table 1.

The main asset is a ground-based scanning X-band (3.2-cm wavelength) dual-polarization Doppler radar (X-Pol; Martner et al. 2001; Matrosov et al. 2005) located at Fort Ross (FRS), California. X-Pol executed both slant-horizontal plan position indicator (PPI) and vertically oriented range-height indicator (RHI) scans (Table 1). PPI scans extended to a maximum range of $57 \mathrm{~km}$ with $0.23-\mathrm{km}$ gate spacing and were repeated at least once every $6 \mathrm{~min}$. The analysis employed PPI scans with a fixed elevation angle of $0.5^{\circ}$ to best resolve lowlevel structures (e.g., beam altitude is $\sim 500 \mathrm{~m}$ MSL at a $40-\mathrm{km}$ range). These scans were only directed offshore because of low-level beam obstruction from the coastal mountains. RHI scans extended to a variable maximum range between 28 and $38 \mathrm{~km}$ with $0.11-\mathrm{km}$ gate spacing and were executed over the ocean and terrain in a cycle 

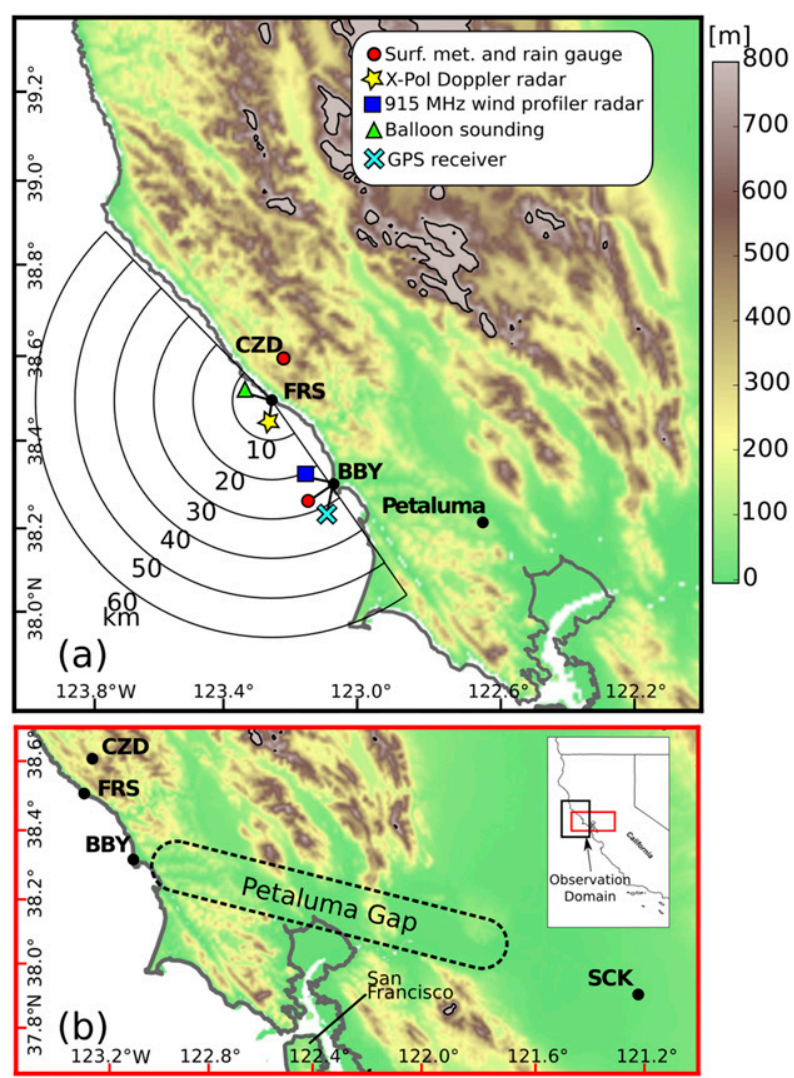

FIG. 1. (a) Topographic map overlaid with observing systems. Legend identifying each instrument along with the color scale for terrain elevation $(\mathrm{m})$ are included. Semicircles centered at Fort Ross (FRS) indicate the X-Pol analysis domain. Location of the city of San Francisco is included. Black contour line over the terrain indicates altitude of $800 \mathrm{~m}$. (b) Topographic map showing Petaluma Gap terrain and the METAR station at Stockton (SCK). Inset map in (b) provides a reference for both topographic maps relative to the coast of Northern California: (a) map (black line); (b) map (red line).

that repeated at least once every $12 \mathrm{~min}$. These scans started by viewing one horizon then rotated upward toward and past zenith, but did not extend all the way down to the opposite horizon. Given the major contribution of LLJs and ARs in the meridional direction (see section 3), the analysis employed RHI scans that were directed in the meridional plane.

Each radar sweep was quality controlled by manually removing artifacts such as ground and sea clutter, range folding (i.e., second trip echo), sidelobe echoes, and by dealiasing folded Doppler radial velocities. After the quality control process, polar-coordinate sweeps were interpolated into a Cartesian grid. For PPI scans, the horizontal and vertical grid spacings were 0.5 and $0.35 \mathrm{~km}$, respectively. For RHI scans, the horizontal and vertical grid spacings were 0.1 and $0.2 \mathrm{~km}$, respectively. A Cressman distance-dependent weighting scheme (Trapp and
Doswell 2000) was employed to interpolate values of attenuation-corrected reflectivity (Matrosov et al. 2005) and Doppler radial velocity to each Cartesian grid point.

A beam obstruction produced by the X-Pol radar trailer over an azimuth sector of $\sim 130^{\circ}-180^{\circ}$ and below $13^{\circ}$ of elevation yielded smaller values of reflectivity because of reduced transmitted power downrange of this beam blockage. The composites of Doppler velocity were not impacted since Doppler velocity is derived from phase shift rather than power. As a result, both PPI and RHI sweeps are used in the composite analysis of Doppler velocity while only PPI sweeps are employed in the composite analysis of reflectivity (see section 4).

Merged vertical cross sections of radial velocity were made by combining north and south RHI scans (e.g., $0^{\circ}$ and $180^{\circ}$ azimuth) for the 9 January, 16-18 February, and 25 February 2004 storms (Table 1). Although the contributing RHI scans were offset by $2-3 \mathrm{~min}$, the structure across the merged interface of the two scans was coherent. The horizontal component of radial velocity in the plane of each cross section was calculated toward north (i.e., meridional wind). Elevation angles between $65^{\circ}$ and $115^{\circ}$ were excluded from the merged radial velocity RHI to simplify both visualization and interpretation of airflow structures.

A 915-MHz wind-profiling radar (Ecklund et al. 1988) located at Bodega Bay, California (BBY), provided hourly profiles of horizontal winds from $\sim 0.1$ to $\sim 4.0 \mathrm{~km} \mathrm{MSL}$ with $\sim 100-\mathrm{m}$ vertical resolution (high-altitude mode). Each profile was processed with the continuity method of Weber et al. (1993) that checks consistency in the dataset over time and height. Vertical profiles of pressure, temperature, relative humidity, and horizontal wind velocity were retrieved from balloon soundings released at FRS with an average vertical resolution of $9 \mathrm{~m}$. In addition, 2-min-resolution surface observations of air temperature, relative humidity, pressure, wind velocity, and precipitation were collected at Cazadero, California (CZD), and BBY. These observations were manually checked for outliers and time consistency. Additional information for the 2004 storms was provided by hourly averaged columnintegrated water vapor (IWV) observations collected at BBY from a ground-based global positioning system (GPS) receiver (Wolfe and Gutman 2000), allowing the evolution of water vapor to be monitored while storms passed over the observing domain. GPS-IWV observations are unaffected by precipitation (Businger et al. 1996).

Data employed in developing the conclusions of this study can be accessed in the Open Science Framework (https://osf.io/kmu8y/). This repository contains surface, wind profiler, and Cartesian X-Pol data along with the corresponding metadata. 


\section{Overview of storms}

Surface rainfall traces from BBY and CZD (Fig. 2) indicate that most of the storms have peak rain rates of $\sim 10-15 \mathrm{~mm} \mathrm{~h}^{-1}$. However, the 16-18 February 2004 storm (Fig. 2f) is characterized by two rain-rate peaks of $\sim 15-20 \mathrm{~mm} \mathrm{~h}^{-1}$. Total accumulated rainfall is consistently larger over the mountains (CZD), with mountainto-coast rainfall ratios between 1.9 and 5.7.

Synoptic context for each storm is provided by analyses from the Climate Forecast System Reanalysis (CFSR; Saha et al. 2010) less than $6 \mathrm{~h}$ before significant precipitation was observed along the coast and over the coastal mountains (Fig. 3). Common features in all the analyses are sea level pressure depressions of $\sim 980-990 \mathrm{hPa}$ centered well offshore of the Washington-Oregon coast (around $45^{\circ} \mathrm{N}, 140^{\circ} \mathrm{W}$ ), integrated water vapor transport (IVT) of at least $250 \mathrm{~kg} \mathrm{~m}^{-1} \mathrm{~s}^{-1}$ associated with either existing or remnants of dissipated ARs, and an equivalent potential temperature $\left(\theta_{e}\right)$ gradient suggesting the approach of a warm advection regime. Tilting isentropes during warm advection would favor enhanced static stability and the formation of TTAs. They differ, however, in the equivalent potential temperature gradients of approaching baroclinic waves. The 16-18 February 2004 storm is characterized by the strongest gradient (Fig. 3f) while the weakest gradient is associated with the 2 February 2004 storm (Fig. 3e). Comparable equivalent potential temperature gradients are evident for the remaining storms. There are also differences in AR characteristics. While the 15-16 February 2003 storm (Fig. 3c) is relatively weak in terms of IVT and the 2 February 2004 storm (Fig. 3e) contains the remnants of a dissipated AR, the storm on 16-18 February 2004 (Fig. 3f) is associated with a strong and clearly defined AR. Orientation of ARs for the storms on 21-23 January 2003 and 9 January 2004 (Figs. 3b,d) is approximately meridional. In contrast, the storms on 12-14 January 2003, 15-16 February 2003, 16-18 February 2004, and 25 February 2004 (Figs. 3a,c,f,g) have ARs with nearly southwest-northeast orientations. However, in these latter cases, the IVT pattern takes on a more meridional orientation closer to the coast, suggesting that the low-level meridional component of flow increases as the ARs approach the continent.

Coastal airflow characteristics of each storm are now examined with data from the $915-\mathrm{MHz}$ wind profiler at BBY (Fig. 4). As a means to highlight LLJ structures, the meridional component of flow is analyzed based on the aforementioned inferences drawn from CFSR data. Further, periods characterized by LLJ conditions are objectively identified using a technique similar to that employed by Neiman et al. (2002). An LLJ is identified 

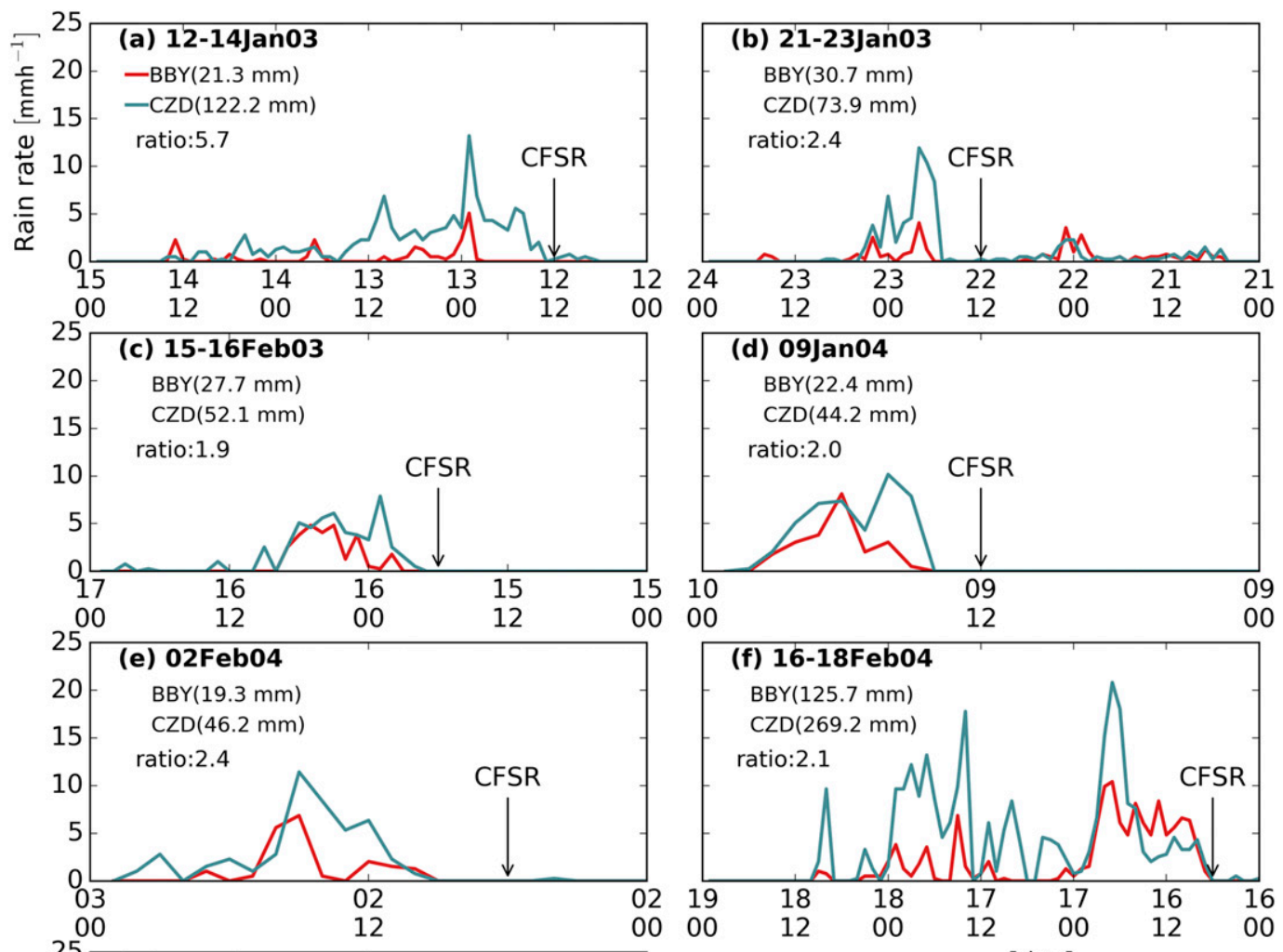

00
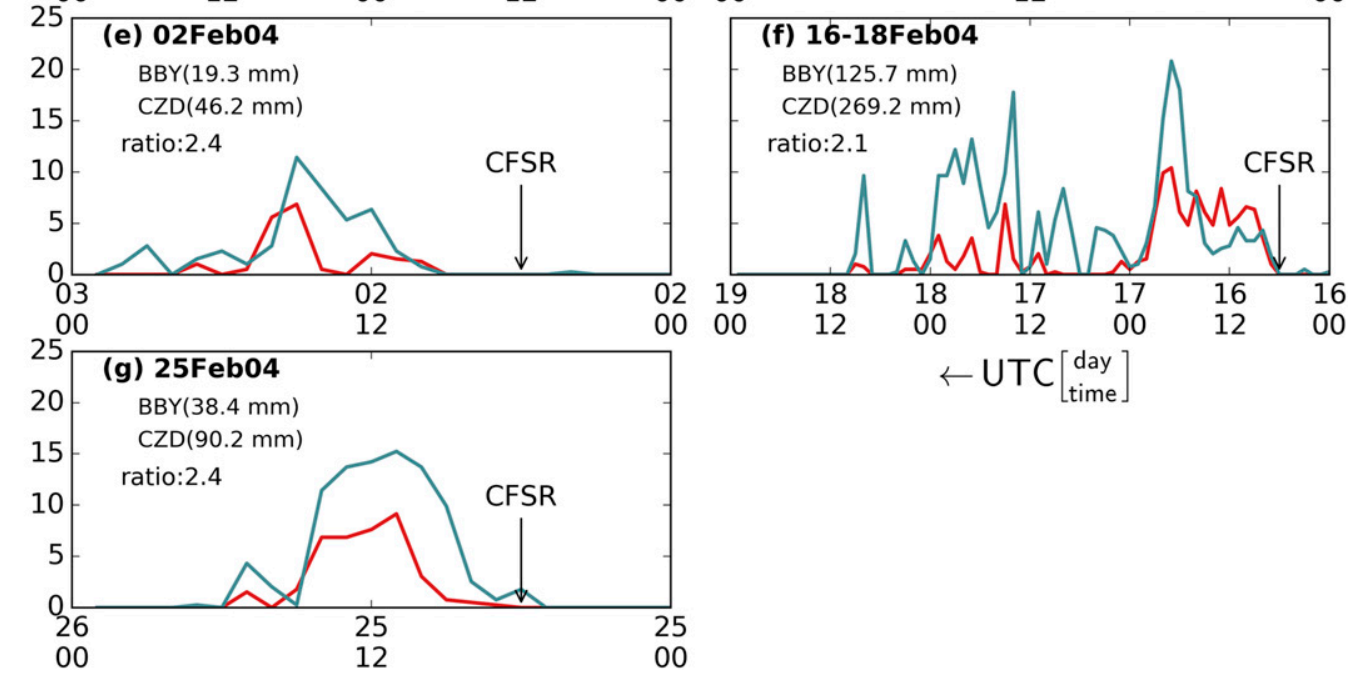

FIG. 2. Time series of hourly rain rates at Bodega Bay (BBY, red line) and Cazadero (CZD, green line). Legend includes total rainfall at each site (shown in parentheses) and mountain to coast (CZD/BBY) rainfall ratio. CFSR annotation indicates analysis time in Fig. 3. Horizontal axis includes the date in the top line and time in UTC in the bottom line. Time increases from right to left to represent the eastward advection of storms.

by searching each profile for a maximum of meridional component wind speed in excess of $10 \mathrm{~m} \mathrm{~s}^{-1}$ located below $1500 \mathrm{~m}$ MSL and underneath a local minimum aloft, with a wind speed difference between the maximum and minimum of at least $2 \mathrm{~m} \mathrm{~s}^{-1}$. LLJ conditions are defined to exist when these specifications are observed for at least two consecutive hours. LLJ structures are evident in all storms with different magnitudes and altitudes. During the 2003 storms (Figs. 4a-c) LLJ magnitudes oscillate between 11 and $19 \mathrm{~m} \mathrm{~s}^{-1}$, exceeding $19 \mathrm{~m} \mathrm{~s}^{-1}$ on 21-23 January 2003. The average LLJ magnitude of this group is $14.4 \mathrm{~m} \mathrm{~s}^{-1}$. LLJ altitudes vary between $\sim 350$ and $1100 \mathrm{~m}$ MSL with an average altitude of $660 \mathrm{~m}$. During the 2004 storms (Figs. 4d-g) LLJ magnitudes exceeding $27 \mathrm{~m} \mathrm{~s}^{-1}$ are observed on
16-18 February and 25 February during relatively long periods, which result in a larger average 2004 LLJ magnitude of $22.1 \mathrm{~m} \mathrm{~s}^{-1}$. The average altitude of these LLJs is also $660 \mathrm{~m}$.

Orographic forcing associated with these LLJs is distilled by examination of upslope wind speed (i.e., component from $230^{\circ}$ ) averaged over the $0.85-1.15-\mathrm{km}$ layer and its product with GPS-IWV called bulk upslope IWV flux (Fig. 5), an approach employed by Neiman et al. (2009) and Kingsmill et al. (2016). All of the storms meet or exceed upslope wind speed and, when available, bulk upslope IWV flux thresholds ( $12.5 \mathrm{~m} \mathrm{~s}^{-1}$ and $25 \mathrm{~cm} \mathrm{~m} \mathrm{~s}^{-1}$, respectively) for AR conditions during at least a portion of their lifetimes. Additionally, it is evident that the maxima in 
Integrated water vapor transport $\left[\mathrm{kgm}^{-1} \mathrm{~s}^{-1}\right]$ Mean sea level pressure $[\mathrm{hPa}]$ Equivalent potential temperature $[\mathrm{K}]$ at $1000 \mathrm{hPa}$

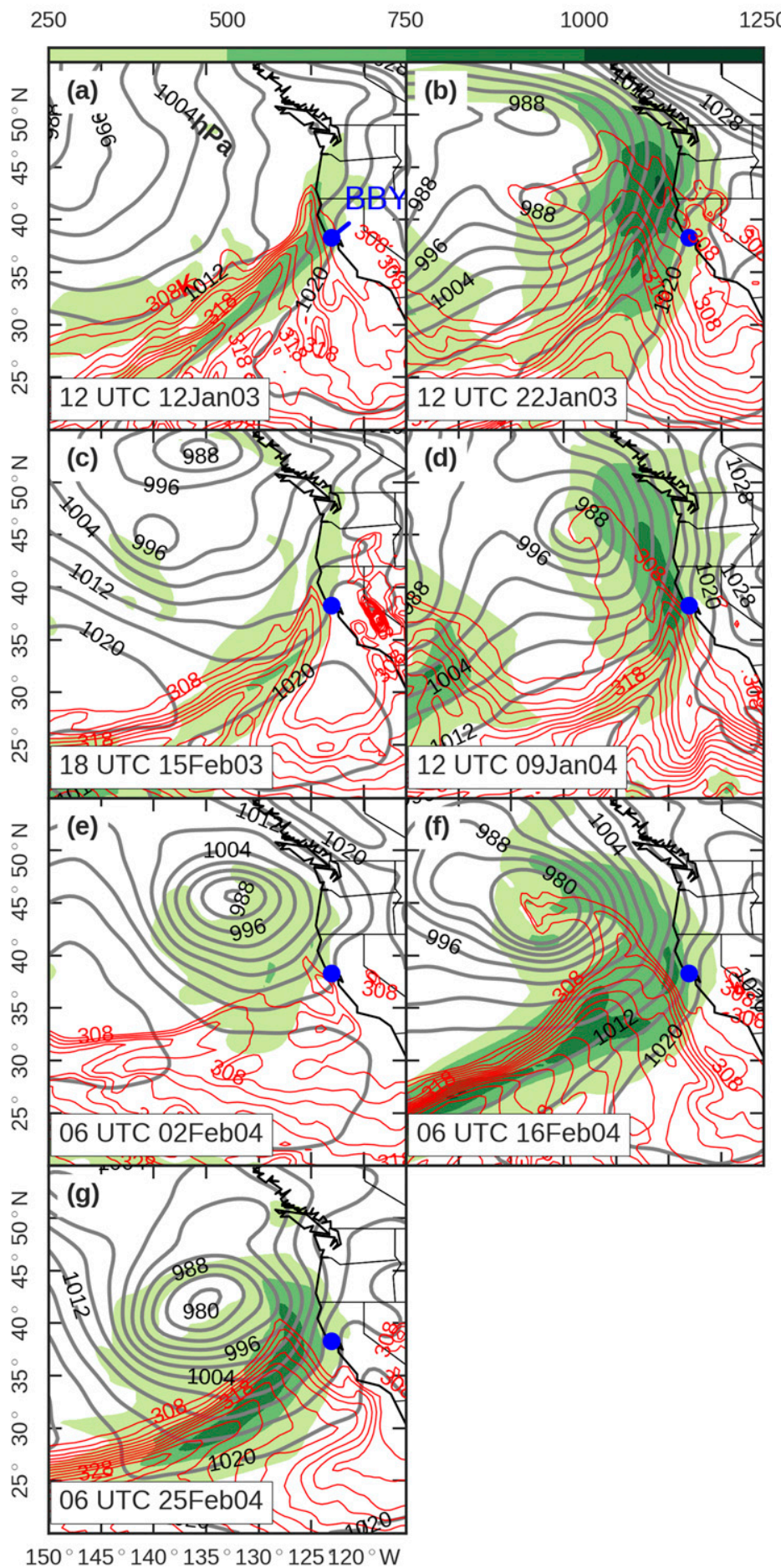

FIG. 3. Reanalysis-derived integrated water vapor transport (IVT, $\mathrm{kg} \mathrm{m}^{-1} \mathrm{~s}^{-1}$, filled contours), mean sea level pressure (hPa, gray contours), and equivalent potential temperature $\left(\theta_{e}\right)$ at $1000 \mathrm{hPa}(\mathrm{K}$, red contours) from the CFSR during 2003 storms at (a) 1200 UTC 12 Jan, (b) 1200 UTC 22 Jan, (c) 1800 
orographic forcing are nearly coincident with CZD rain-rate maxima (Fig. 2).

\section{Kinematic and precipitation structures}

\section{a. X-Pol analysis approach}

Figure 4 shows the time coverage of X-Pol observations and the TTA periods for each of the seven storms determined with the objective identification method of Part I: 0-500-m MSL layer-mean wind direction between $0^{\circ}$ and $150^{\circ}$ during at least $2 \mathrm{~h}$ applied to hours when rain rate at CZD is $\geq 0.25 \mathrm{~mm} \mathrm{~h}^{-1}$. The requirement of measurable precipitation at CZD is employed since the focus of this study is on the linkage between TTAs and orographic rainfall. Two of the storms (15-16 February 2003 and 25 February 2004) did not experience any TTA conditions. The 12-14 January 2003 storm presented a TTA hiatus on 12 January between 1100 and 1200 UTC. NO-TTA periods are defined by times with X-Pol observations (Table 1) but outside of TTA periods. X-Pol sweeps were partitioned into TTA and NO-TTA periods and combined to investigate composite structures. The seven-storm composite as a whole is examined first and then individual storm composites are examined to evaluate interstorm variability.

Composited kinematic structures were determined by time-averaging Doppler velocity, similar to the VK15 approach. Composited precipitation structures were determined by deriving the frequency of attenuationcorrected reflectivity exceeding a given threshold. Yuter et al. (2011) employed a similar approach to examine precipitation structures near Portland, Oregon, with operational radar observations. They used this methodology to minimize the impacts of biases from the radar bright band in deducing the spatial distribution of precipitation. Yuter et al. (2011) applied exceedance of equivalent reflectivity thresholds of 13 and $25 \mathrm{~dB} Z_{e}$ (corresponding to rain rates of $\sim 0.2$ and $1.3 \mathrm{~mm} \mathrm{~h}^{-1}$, respectively) to a composite of 117 winter storms observed between 2003 and 2006, an approach that worked well for their relatively large radar dataset. However, the present study includes just seven storms and focuses not only on the seven-storm composite but also on the interstorm variability, which increases the potential impact of reflectivity-magnitude variabilities from storm to storm and from different airflow regimes (i.e., TTA vs NO-TTA).

As a means to reduce inter- and intrastorm variability impacts, exceedance thresholds were based on the median value of reflectivity for each grouping of X-Pol data analyzed. The median depends only on the cumulative frequency distribution of reflectivity in each group and, among central tendency metrics, has the advantage of being less sensitive to variations in extreme values. Exceedance frequency for each radar grid point of each $\mathrm{X}-\mathrm{Pol}$ group was computed by summing radar grid points greater than or equal to the median of the corresponding cumulative frequency distribution, dividing by the total number of radar grid points in the group, and multiplying by 100 to obtain a percentage. In the rest of the paper the term "precipitation structure" is used when referring to the structure derived from the exceedance frequency analysis. Similarly, the term "precipitation enhancement" is used when this structure indicates a maximum.

TTA and NO-TTA median values of PPI sweeps are nearly the same for the seven-storm composite (Fig. 6a), but the individual-storm composites have TTA median values that are sometimes stronger and sometimes weaker than NO-TTA median values. One source of variation might be linked with differences in the LLJ magnitude (e.g., Fig. 4), such that stronger (weaker) LLJs would produce stronger (weaker) uplift in the LLJ-TTA interface (e.g., VK15) and thus faster (slower) condensation rates, favoring (hindering) precipitation growth.

The X-Pol RHI observation domain (i.e., maximum range and elevation angle) varied between storms (Table 1), which produced spatial discontinuities in seven-storm composite vertical structures. To mitigate this problem and improve interpretation, the smallest maximum range of the various RHI scans is used. In addition, RHIs from the 2 February 2004 storm were removed from the seven-storm vertical composite analysis because the lowest elevation angle offshore did not extend low enough to allow a clear view and analysis of the TTA and LLJ interaction. The removal of 2 February 2004 RHI scans from the seven-storm composite analysis did not fundamentally influence the resulting kinematic structures other than to eliminate spatial discontinuities.

UTC 15 Feb, and 2004 storms at (d) 1200 UTC 9 Jan, (e) 0600 UTC 2 Feb, (f) $0600 \mathrm{UTC} 16 \mathrm{Feb}$, and (g) $0600 \mathrm{UTC} 25 \mathrm{Feb}$. The $\theta_{e}$ contours included between 308 and $338 \mathrm{~K}$ at every $2 \mathrm{~K}$. 

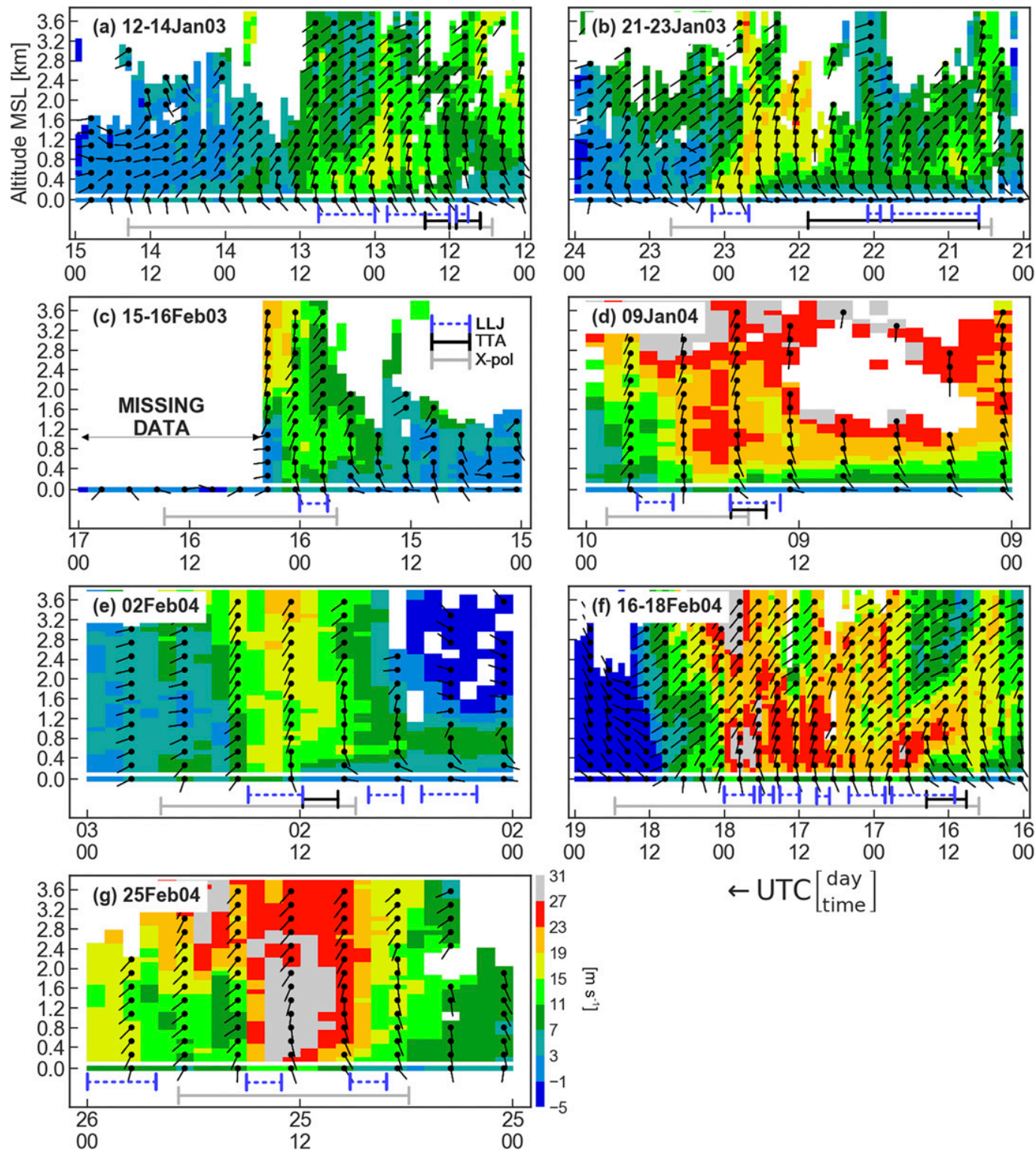

FIG. 4. Time-height analyses of meridional wind speed (color coded) and total wind direction (wind staff) observed at Bodega Bay (BBY) from the $915-\mathrm{MHz}$ wind profiling radar for each of the storms indicated in Table 1. Some of the storms have extended periods relative to Table 1 to provide better context. Each panel includes time interval of LLJ (blue dashed line), TTA periods (black line), and X-Pol observations at Fort Ross (FRS, gray line) at the bottom. First level in each analysis is derived from surface observations. Horizontal axis includes the date in the top line and time in UTC in the bottom line. Time increases from right to left to represent the eastward advection of storms.

\section{b. Seven-storm composite}

Figure 7 presents TTA (Figs. 7a,c,e) and NO-TTA (Figs. 7b,d,f) structures composited from the seven storms. The TTA composite includes a total of 428 sweeps (293 PPI and 135 RHI) while the NO-TTA composite comprises a total of 2390 sweeps (1757 PPI and $633 \mathrm{RHI})$.
In terms of kinematic structure, the horizontal TTA composite shows a sharper curvature of the isoline of zero radial velocity (hereafter called the zero isodop, Fig. 7a) compared to the NO-TTA composite (Fig. 7b). The airflow associated with the TTA composite is characterized by inferred southeasterly winds from the coast out to $\sim 20 \mathrm{~km}$ offshore, southerly winds beyond $\sim 40 \mathrm{~km}$, and a transition zone from $\sim 20$ to $40 \mathrm{~km}$. In 

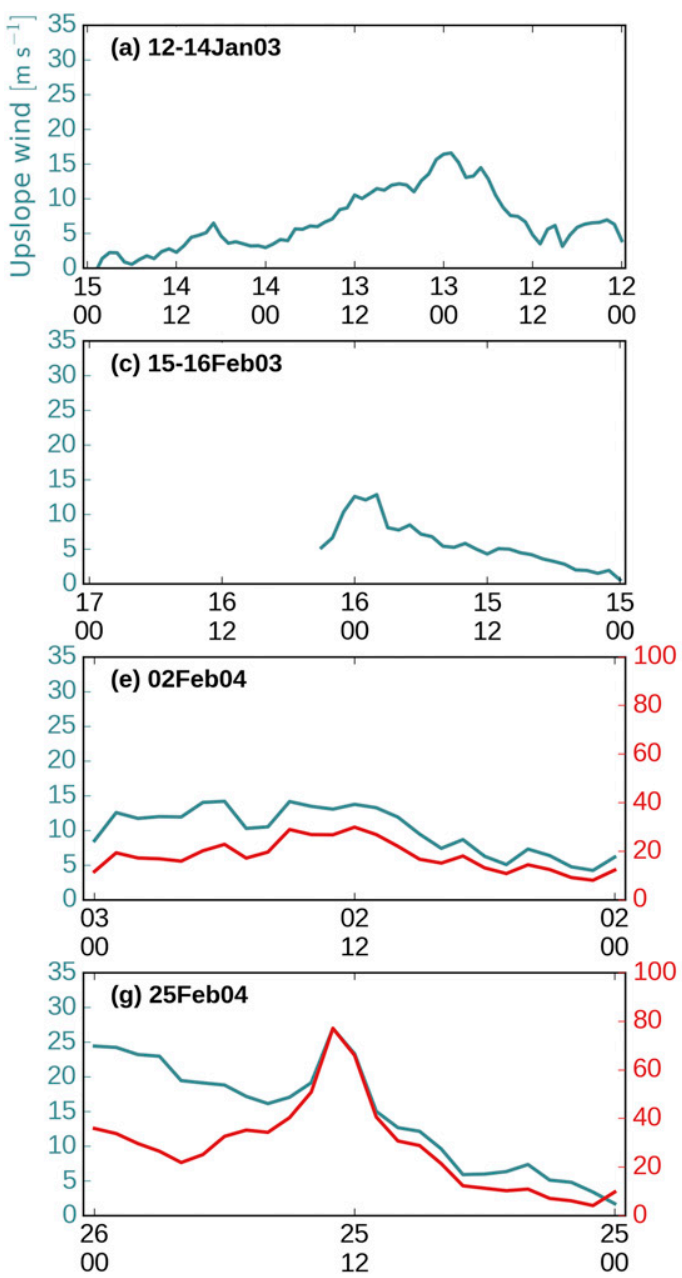

FIG. 5. Time series of upslope wind (from $230^{\circ}, \mathrm{m} \mathrm{s}^{-1}$, green line) and bulk water vapor flux ( $\mathrm{cm} \mathrm{m} \mathrm{s}^{-1}$, red line) at Bodega Bay (BBY). Storms during 2003 only have upslope wind available. Horizontal axis includes the date in the top line and time in UTC in the bottom line. Time increases from right to left to represent the eastward advection of storms. contrast, the airflow associated with the NO-TTA composite is characterized by inferred southeasterly winds out to $\sim 10 \mathrm{~km}$ offshore, southerly winds beyond $\sim 30 \mathrm{~km}$, and a transition zone from $\sim 10$ to $\sim 30 \mathrm{~km}$. There are also variations in the location and strength of LLJ structures. The TTA composite (Fig. 7a) shows maximum inbound radial velocities of $\sim-18 \mathrm{~m} \mathrm{~s}^{-1}$ located south of the radar at ranges beyond $\sim 35 \mathrm{~km}$ that are associated with LLJ structures upstream of TTAs. This differs from the NO-TTA composite (Fig. 7b) where maximum inbound radial velocities are smaller $\left(\sim-14 \mathrm{~m} \mathrm{~s}^{-1}\right)$ and located closer to the radar at ranges beyond $\sim 20 \mathrm{~km}$.

The vertical TTA composite (Fig. 7c) depicts a meridional LLJ exceeding $20 \mathrm{~m} \mathrm{~s}^{-1}$ riding up and over a weaker airflow of less than $10 \mathrm{~m} \mathrm{~s}^{-1}$ extending from the coast to $\sim 15 \mathrm{~km}$ offshore and less than $0.5-\mathrm{km}$ depth at the coast, corresponding to the TTA. This vertical structure is
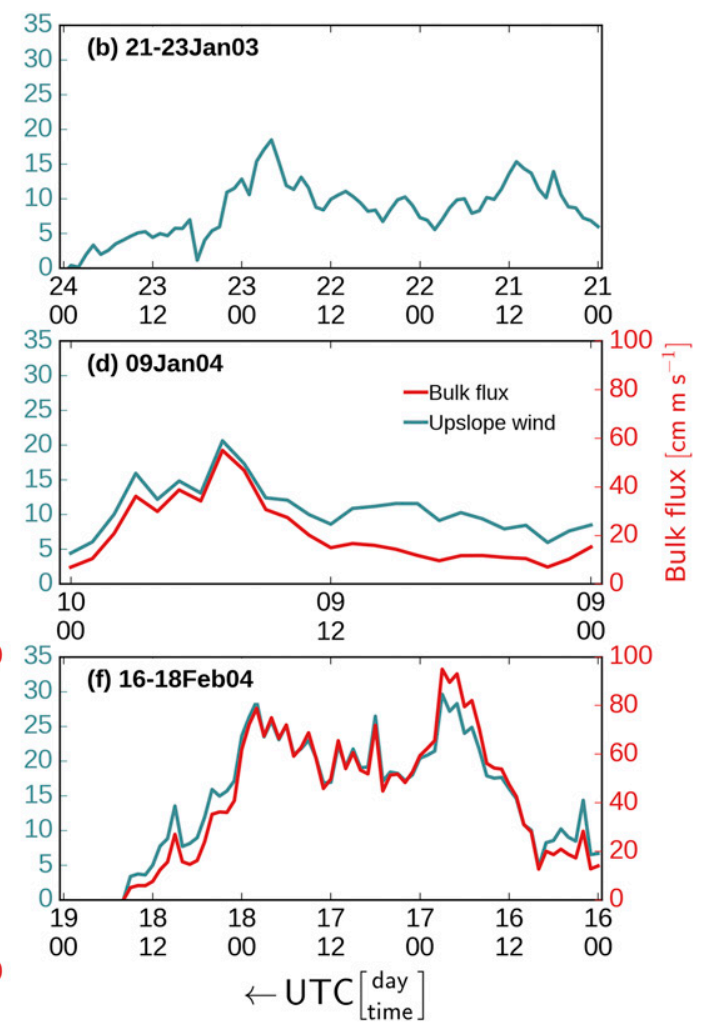

comparable to the TTA vertical structure described by VK15. The mean altitude of the LLJ shifts from $\sim 0.5 \mathrm{~km}$ MSL at a $\sim 30$-km range to $\sim 1.0 \mathrm{~km}$ MSL over the radar.

It is important to note that inferred lifting of the LLJ is not derived directly from vertical velocity observations but rather from the combined analysis of the synoptic context (section 3) and X-Pol radial velocity observed in RHI sweeps. CFSR wind fields associated with each storm indicate a significant northward-directed component of airflow near the coast of Northern California and at levels below $750 \mathrm{hPa}$ (not shown). In addition, the warm advection pattern evident near the coast in each storm (Fig. 3) suggests tilted isentropes along the coastal area and increasing static stability at lower levels, possibly contributing to the formation of TTAs. Considering that the incoming moist airflow transported by the LLJ (i.e., the AR) possesses near-neutral static stability 


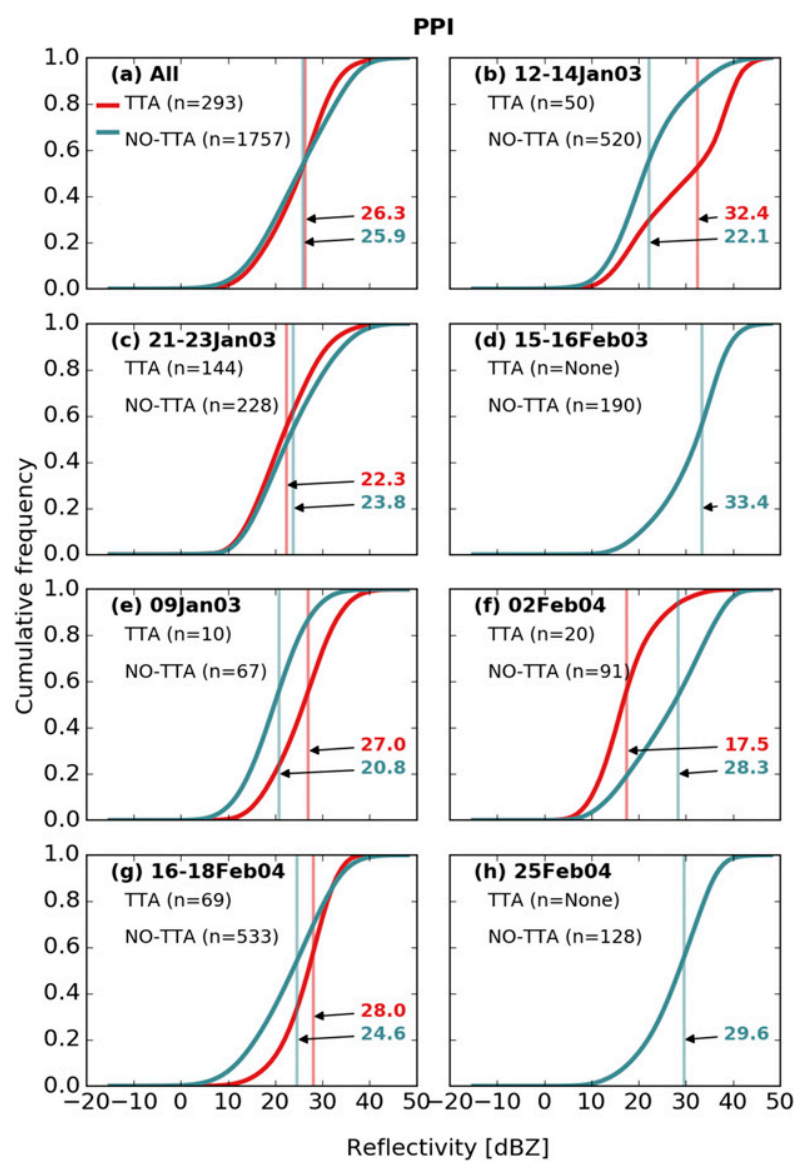

FIG. 6. Cumulative frequency distribution (CFD) of attenuatedcorrected reflectivity for plan position indicator (PPI) scans in each of the seven storms and separated into TTA and NO-TTA groups. Vertical lines indicate median values.

(e.g., Ralph et al. 2005; Neiman et al. 2008), the isentropic lift of the approaching LLJ over the TTA can be expected. Indeed, the meridional component of airflow observed with X-Pol RHI scans indicates that a strong LLJ airflow curves upward well before reaching the coast. An approximate steady-state LLJ structure is assumed by computing the mean radial velocity in RHI fields over relatively long periods. In addition, the lifting of the LLJ inferred from the RHI structures is also supported by previous studies (e.g., Neiman et al. 2002; Kingsmill et al. 2013). In VK15, similar LLJ lifting structures were documented in detail. Of course, these assumptions are not always met, so less clearly defined LLJs might be apparent in our results because of an airflow more perpendicular to the meridional RHI plane. Nevertheless, isentropic lifting of the LLJ over the TTA is still a plausible interpretation of these kinematic structures.

The vertical NO-TTA composite (Fig. 7d) has a meridional flow structure that does not clearly indicate the presence of a LLJ, a result that requires some explanation. The NO-TTA composite is associated with a relatively large fraction of X-Pol observation time (Fig. 4) compared with the total LLJ duration. Therefore, LLJ structures that are present during NO-TTA conditions are smoothed out by the longer NO-TTA sampling period, including times after the baroclinic wave passage. This also explains the weaker LLJ signature observed for NO-TTA conditions in the PPI composite (Fig. 7b). More details about this result are provided in section 4c.

Examination of the horizontal TTA precipitation structure indicates a relatively large frequency of echoes exceeding the median reflectivity of $26.3 \mathrm{~dB} Z_{e}$ at $\sim 5-25 \mathrm{~km}$ offshore from the coast (Fig. 7e). In contrast, the NO-TTA composite shows relatively large median-reflectivity $\left(25.9 \mathrm{~dB} Z_{e}\right)$ exceedance frequencies that are in closer proximity to the coast and only extend offshore $\sim 15 \mathrm{~km}$ (Fig. 7f). In both cases, the reflectivity frequency maximum approximately parallels the coast.

Results from the seven-storm composite analysis show that TTA and NO-TTA periods are associated with two distinct kinematic and precipitation structures. These structures suggest that TTAs are connected with mean LLJ altitude elevating toward the coast and enhanced exceedance frequency upstream of the coastal mountains out to a range of $\sim 20 \mathrm{~km}$ from the coast. Conversely, NO-TTA periods are associated with a more homogeneous kinematic structure and enhanced exceedance frequency closer to the coastal mountains.

\section{c. Interstorm variability}

The seven-storm-composite analysis depicts average TTA and NO-TTA kinematic and precipitation structures but does not provide context about interstorm variability. In this section, details about the kinematic and precipitation structures for individual storms that compose the composite are examined. As mentioned before, TTA conditions were not observed for the 15-16 February 2003 and 25 February 2004 storms.

The horizontal kinematic structures of TTA periods observed during 12-14 January 2003, 21-23 January 2003, 9 January 2004, 2 February 2004, and 16-18 February 2004 storms (Figs. 8a,c,e,g,i) exhibit a relatively consistent pattern in the shape of the zero isodop: inferred southeasterly winds are observed from the coast out to a distance of $\sim 20 \mathrm{~km}$, followed by a transition zone of southeasterly to southerly winds from $\sim 20$ to $\sim 30 \mathrm{~km}$, and then southerly to south-southwesterly winds beyond $\sim 30 \mathrm{~km}$. During 12-14 January 2003 (Fig. 8a) the zero isodop transition is somewhat smoother, likely produced by a synoptic pattern with larger south-southeasterly component flow and thus a smaller difference relative to the southeasterly winds associated with the TTA, which is 
TTA

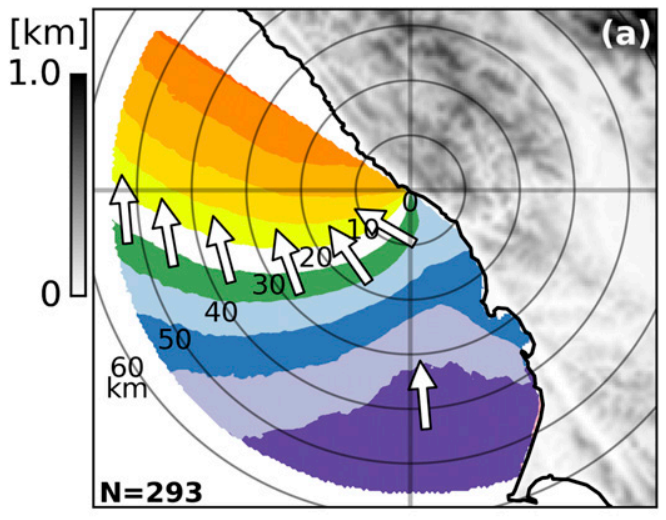

NO-TTA

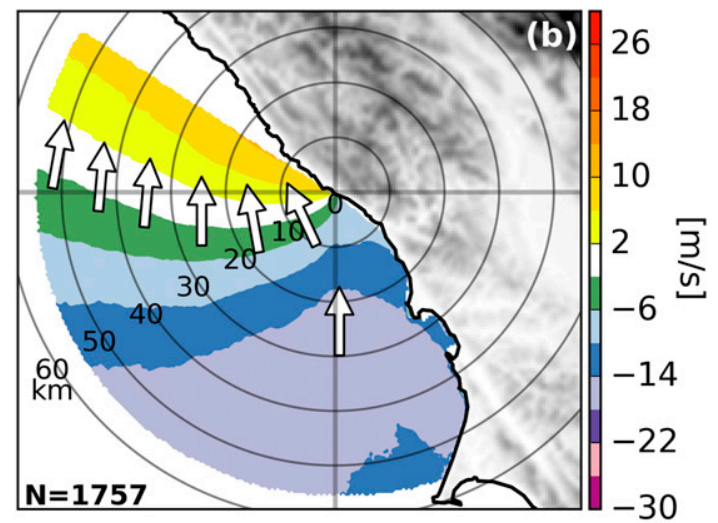

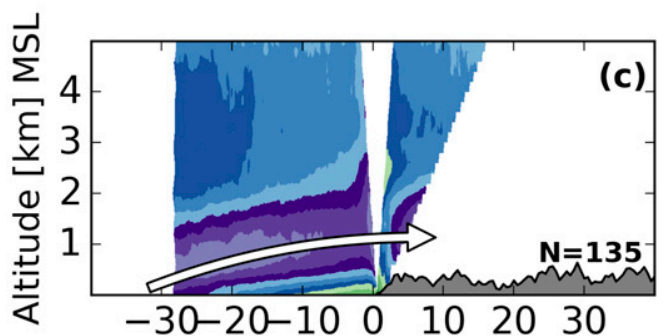
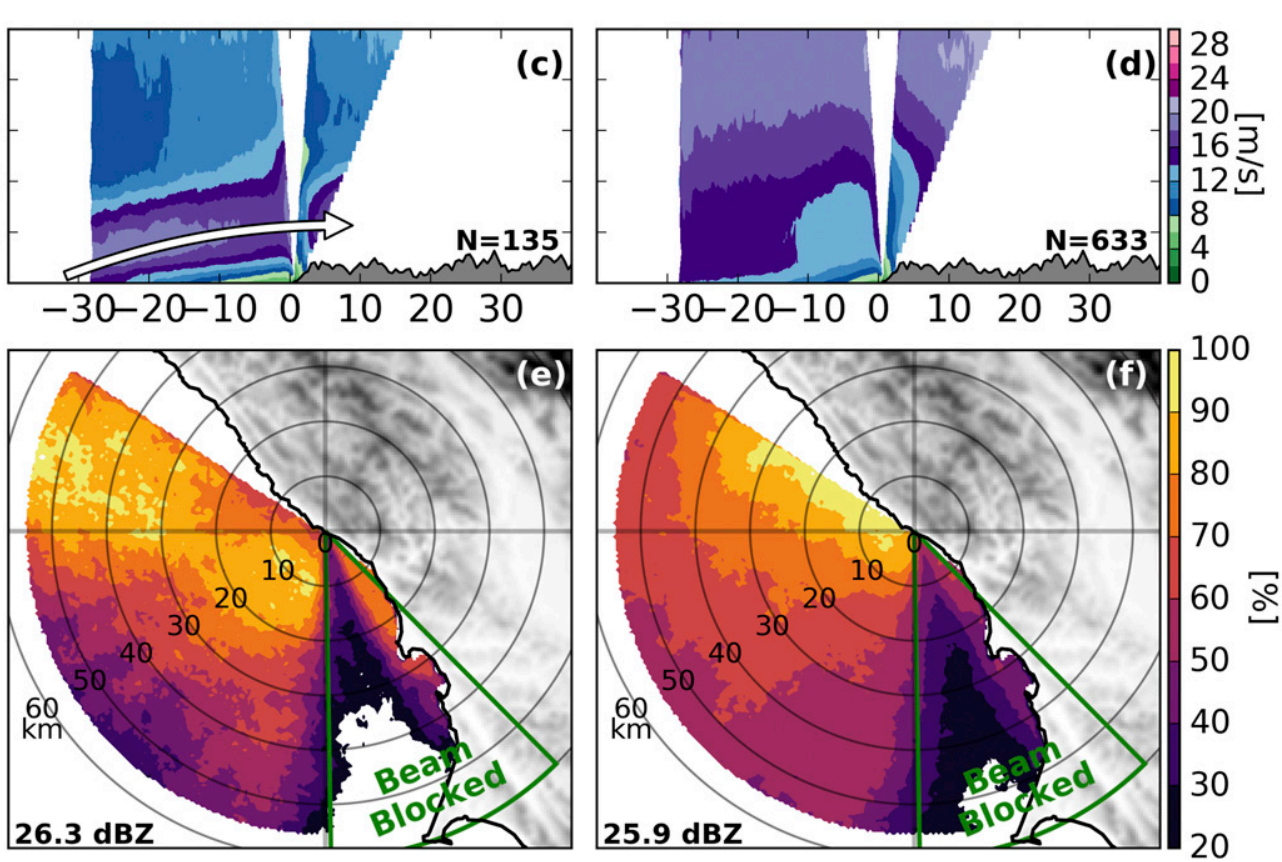

FIG. 7. Time composite analysis of X-Pol observations during (left) TTA and (right) NO-TTA periods for the seven storms: average (a),(b) horizontal and (c),(d) vertical kinematic structures derived from Doppler radial velocity; normalized frequency of exceeding threshold for horizontal (e),(f) attenuation-corrected reflectivity. Vertical sections are meridionally oriented (i.e., azimuth $0^{\circ}-180^{\circ}$ ). Beam blockage by the radar trailer is indicated in (e),(f). Vertical sections in (c),(d) exclude the 2 Feb 2004 storm (see text for details). Arrows were added over the zero isodop [white contour in (a),(b)] to facilitate wind field interpretation. Single arrows south of the radar in (a),(b),(c) indicate maximum radial velocity associated with low-level jets. Total number of sweeps $(N)$ and median reflectivity values corresponding to each TTA/NO-TTA group is included.

suggested by CFSR analyses (not shown). Maximum inbound radial velocities south of the radar vary from $\sim-10$ to $-18 \mathrm{~m} \mathrm{~s}^{-1}$ for all of these storms except 9 January 2004 and 16-18 February 2004 (Figs. 8e,j) when they fluctuate between $\sim-22$ and $-30 \mathrm{~m} \mathrm{~s}^{-1}$.

Median-reflectivity exceedance frequencies during TTA conditions depict horizontal precipitation structures with offshore enhancement that are approximately parallel to the coast during 2 February 2004 and
16-18 February 2004 (Figs. 8h,j) located $\sim 10-20 \mathrm{~km}$ offshore. The 21-23 January 2003 storm (Fig. 8d) also suggests a roughly parallel structure $\sim 20-30 \mathrm{~km}$ offshore but it is less elongated and accompanied by a nearly coast-perpendicular enhancement within $20 \mathrm{~km}$ of the coast. The 12-14 January 2003 storm (Fig. 8b) presents a precipitation structure with the strongest echoes located to the north of the domain, precluding the assessment of the geometrical characteristics of its 
TTA
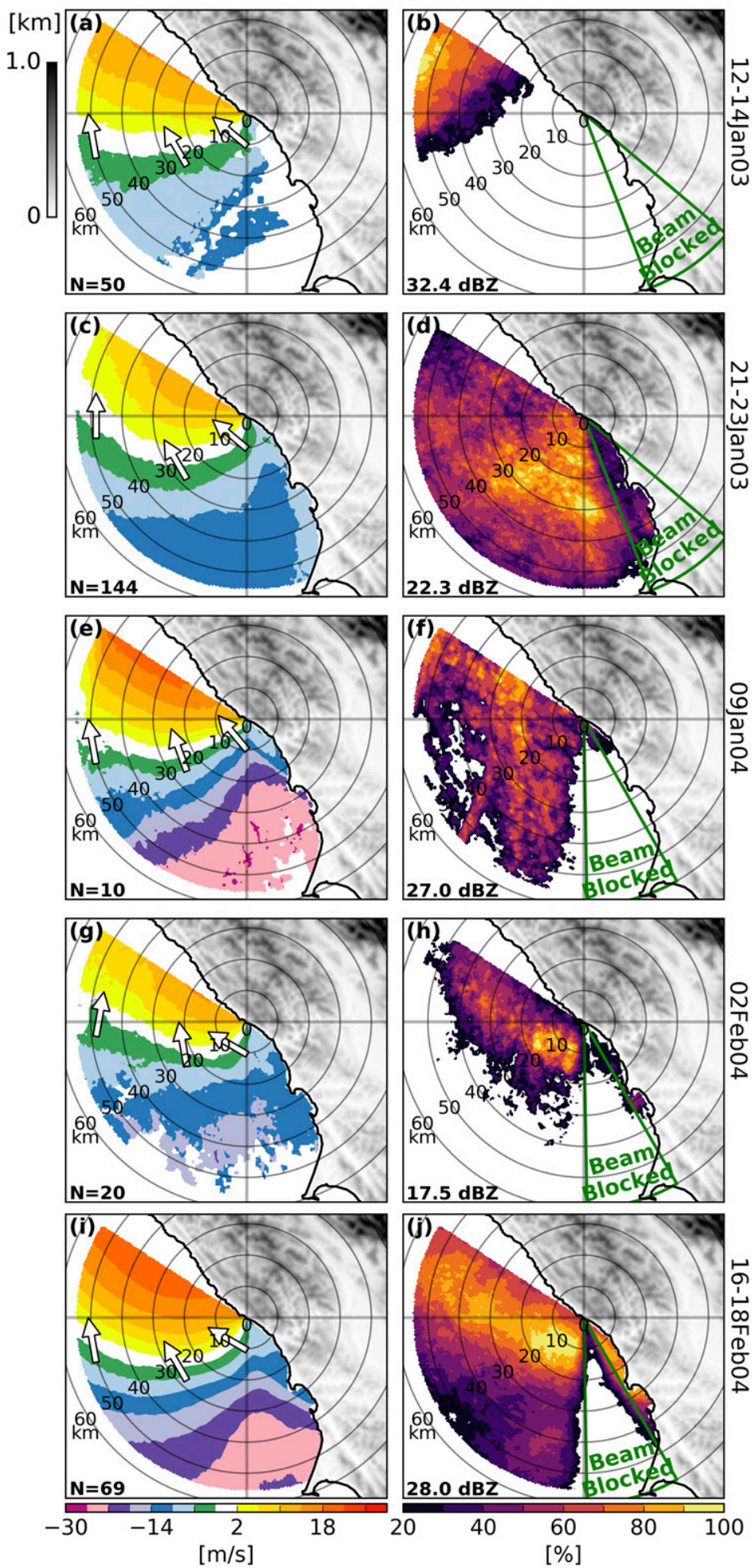

FIG. 8. (left) Horizontal kinematic and (right) precipitation structures for individual storms during TTA periods of (a),(b) 12-14 Jan 2003; (c),(d) 21-23 Jan 2003; (e),(f) 9 Jan 2004; (g),(h) 2 Feb 2004; and (i),(j) 16-18 Feb 2004. Number of sweeps $(N)$ in each analysis, reflectivity threshold, and rings indicating range from X-Pol are included. See Fig. 4 for details of each TTA period. Beam blockage by the radar trailer is indicated. 
enhancement. Finally, the 9 January 2004 storm has only $1 \mathrm{~h}$ of X-Pol observations during TTA conditions $(n=$ 10, Fig. 8f), which makes precipitation-enhancement patterns difficult to detect because of a relatively small sample size. Although the pattern of 2 February 2004 is clearly defined, it might also be affected by the relatively short duration of X-Pol observations $(2 \mathrm{~h})$ and correspondingly small sample size $(n=20)$.

Vertical kinematic structures for TTA periods (Fig. 9) are generally characterized by meridional LLJs riding up and over a weaker airflow that corresponds to the TTA. Also, there are some nontrivial storm-to-storm differences. X-Pol observations during the 12-14 January 2003 and 9 January 2004 storms (Figs. 9a,c) capture only a fraction of the TTA period when the meridional LLJ is relatively weak or absent (Figs. 4a,d). Yet, it is evident that meridional winds of $\sim 12$ and $26 \mathrm{~m} \mathrm{~s}^{-1}$, respectively, ride up and over a weaker airflow of $\sim 10$ and $12 \mathrm{~m} \mathrm{~s}^{-1}$, respectively, although the LLJ interpretation for the 9 January 2004 storm is affected by a small number of vertical scans $(n=5)$. The 21-23 January 2003 storm (Fig. 9b) shows an LLJ structure with meridional winds of $\sim 14 \mathrm{~m} \mathrm{~s}^{-1}$ riding up and over a $\sim 10 \mathrm{~m} \mathrm{~s}^{-1}$ airflow associated with the TTA. X-Pol observations during the 2 February 2004 storm (Fig. 9d) also capture only a fraction of the TTA period when the LLJ is weak or absent (Fig. 4e). In addition, a lack of low-level observations offshore prevents a clear depiction of the LLJ and TTA. The 16-18 February 2004 storm (Fig. 9e) is characterized by the strongest and most clearly defined LLJ with meridional winds of $\sim 24 \mathrm{~m} \mathrm{~s}^{-1}$ being lifted above an $\sim 12 \mathrm{~m} \mathrm{~s}^{-1}$ airflow associated with the TTA from $\sim 0.5 \mathrm{~km}$ MSL offshore to $\sim 1.0$ MSL over the coastal mountains.

To strike a contrast with the TTA kinematic and precipitation structures just discussed, attention is now shifted to the interstorm variability of corresponding NO-TTA periods. The zero isodop associated with 12-14 January 2003, 21-23 January 2003, and 16-18 February 2004 storms (Figs. 10a,c,i) exhibits a curvature between ranges of $\sim 10-30 \mathrm{~km}$ and then is less curved at distances further offshore. These structures also feature a zero isodop crossing from the southwest to the northwest quadrant of X-Pol, with inferred south to southwesterly winds beyond $15 \mathrm{~km}$ range. Maximum inbound radial velocities south of the radar for these storms are $-18,-18$, and $-26 \mathrm{~m} \mathrm{~s}^{-1}$, respectively. The corresponding TTA composites for these storms (Figs. 8a,c,i) have zero-isodop features located mostly in the southwest quadrant of X-Pol (i.e., inferred south to southeasterly winds) with greater curvature implying larger horizontal shear of wind direction. The 9 January 2004 storm (Fig. 10e) depicts a curvature between $\sim 10$ and $20 \mathrm{~km}$ offshore, while the
2 February 2004 storm (Fig. 10g) shows a continuous curvature along the zero isodop. These latter storms exhibit stronger southwesterly component flow beyond $20 \mathrm{~km}$ (e.g., zero-isodop in the northwest quadrant) and maximum inbound radial velocities of -18 and $-14 \mathrm{~m} \mathrm{~s}^{-1}$, respectively.

Median-reflectivity exceedance frequencies during NO-TTA conditions on 12-14 January 2003 (Fig. 10b) portray a pattern with precipitation enhancement concentrated within $\sim 10 \mathrm{~km}$ of the coast. The 21-23 January 2003 case (Fig. 10d) also shows precipitation enhancement concentrated within $\sim 10 \mathrm{~km}$ of the coast but embedded in a more inhomogeneous distribution of precipitation. Although characterized by a lower amplitude relative to the previous cases, the 16-18 February 2004 storm (Fig. 10j) exhibits a homogeneous distribution of precipitation with enhanced exceedance frequencies of $>70 \%$ close to the coast extending $\sim 10-15 \mathrm{~km}$ offshore south-southwest of X-Pol out to $\sim 20-25 \mathrm{~km}$ offshore west-northwest of X-Pol. These precipitation enhancement patterns closer to the coast are in agreement with VK15, whose results show that the precipitation enhancement area moves onshore as the TTA weakens and the LLJ-TTA interface approaches the coast. Since there is a gap in the radar coverage just offshore of the coast northwest of the radar, it is not possible to determine if these precipitation enhancements are also confined to similar ranges within the radar coverage gap. The 9 January and 2 February 2004 storms indicate just a slight enhancement near the coast but, unlike the other two cases, the structure relative to the orography is less clear (Figs. 10f,h).

Vertical kinematic structures for NO-TTA periods indicate the apparent absence of a LLJ during 12-14 January 2003, 21-23 January 2003, and 9 January 2004 (Figs. 11a-c), and a weak LLJ during 16-18 February 2004 (Fig. 11e). Missing low-level observations during 2 February 2004 prevent confirmation or rejection of LLJ existence (Fig. 11d). Another characteristic is the weak meridional wind within $10 \mathrm{~km}$ of the coast and below $500 \mathrm{~m}$ MSL (Figs. 11a-c,e). At first glance, this structure seems similar to what is observed during TTA conditions, just with a shorter offshore extension. By definition, this NO-TTA grouping of X-pol data is based on application of the TTA objective identification at BBY (Part I). However, the observed structure is confined to an area so close to the radar that it may not be in effect near BBY, which would be consistent with the NOTTA designation. Given its apparently small scale, one possible explanation for this structure might be a smallerscale TTA unresolved by wind profiler observations at BBY. Another explanation might be meridional wind deceleration and convergence produced by differential sea-land friction (e.g., Doyle 1997; Colle et al. 2008). 


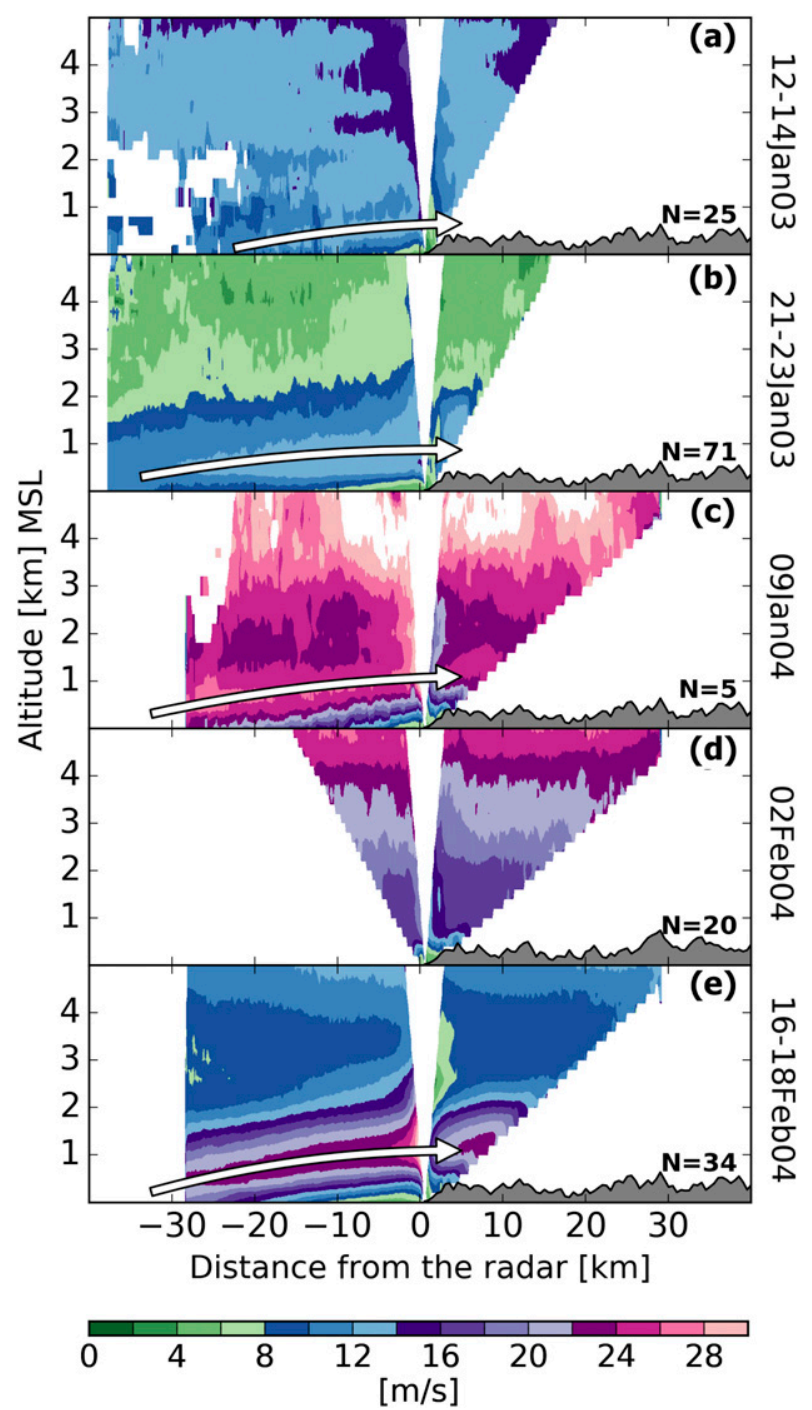

FIG. 9. Vertical kinematic structures for individual storms during TTA periods of (a) 12-14 Jan 2003, (b) 21-23 Jan 2003, (c) 9 Jan 2004, (d) 2 Feb 2004, and (e) 16-18 Feb 2004. Arrows indicate location of low-level jet.

Although LLJ structures are observed in individual XPol scans during NO-TTA periods, the structures tend to be smoothed out in NO-TTA composites as a result of the relatively short duration of LLJs within X-Pol sampling of NO-TTA conditions (Fig. 4). After refining the NO-TTA composite to only include periods with LLJ structures as identified with the BBY wind profiler, distinct LLJ features become apparent in the X-Pol data (Fig. 12). For example, the vertical kinematic structure on 16-18 February 2004 (Fig. 12e) shows a shallow layer of 20-22 $\mathrm{m} \mathrm{s}^{-1}$ meridional component airflow centered at $\sim 0.5 \mathrm{~km}$ that starts rising about $5-10 \mathrm{~km}$ offshore, implying an ascent of the LLJ over the coastal mountains. In contrast, the corresponding vertical kinematic structure observed during TTA conditions on 16-18 February 2004 (Fig. 9e) shows a layer of $22-24 \mathrm{~m} \mathrm{~s}^{-1}$ meridional component airflow centered at $\sim 0.5 \mathrm{~km}$ that starts rising about $25-30 \mathrm{~km}$ offshore. LLJ structures are also clearly evident in the 1214 January and 21-23 January 2003 storms (Figs. 12a,b). However, the 9 January 2004 storm shows no LLJ structure and the 2 February 2004 storm is not accompanied by the low-level observations required to evaluate the presence of a LLJ structure (Figs. 12c,d).

\section{d. Sampling issues}

One of the limitations with this study is the variable number of sweeps between storms, scan strategies (i.e., PPI, RHI), and airflow regimes (i.e., TTA, NO-TTA). For example, the PPI-TTA group comprises 144 sweeps for the 21-23 January 2003 storm (Fig. 8c) but only 10 sweeps for the 9 January 2004 storm (Fig. 8e). More generally, the interstorm variability analysis (Figs. 8-11), suggests that only two storms may be the dominant contributors determining the structure in the sevenstorm composite analyses shown in Fig. 7, especially in terms of precipitation structure. To assess the representativeness of these composite structures, a random sampling without replacement was performed (Wilks 2011). The mean of the Doppler velocity field was computed and the median of the random sample was employed as the threshold to derive exceedance frequency for precipitation structures (see section 4a). With this approach, instead of taking the entire population of sweeps from each storm, a fixed and randomly selected number of sweeps were included in the composite. The sample size of each storm corresponds to the smallest population of the group (e.g., the minimum number of sweeps), that in our case is determined by the 9 January 2003 storm (Fig. 6). In this way, the random composites are constructed from a uniform number of sweeps from each storm, scan-strategy, and airflow-regime grouping. This approach also prevents redundant sampling from the 9 January 2003 storm that could bias the random composite toward the characteristics of this storm. A total of 100 random composites were computed for each group (PPI-TTA, PPI-NO-TTA, RHI-TTA, RHI-NO-TTA) and the mean random composite was considered.

The mean random composites of radial velocity (not shown) indicate no significant structural difference with the corresponding seven-storm composites shown in Figs. 7a-d. In terms of the mean random composites of median-reflectivity exceedance frequency (Fig. 13), the most notable difference is in the TTA regime. The mean random composite (Fig. 13a) suggests a similar maximum offshore but a less organized structure compared to the corresponding seven-storm-composite PPI (Fig. 7e). In 


\section{NO-TTA}
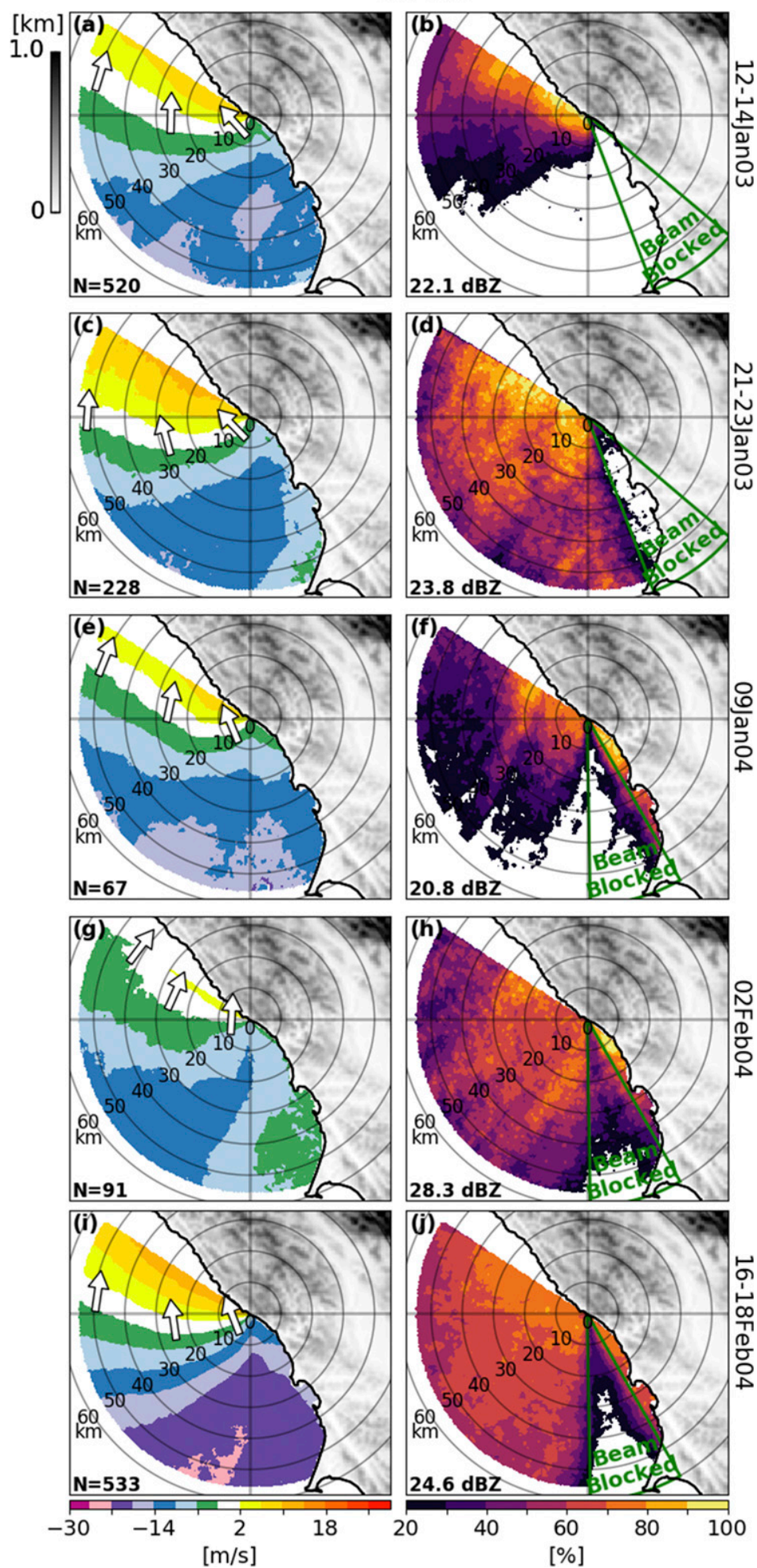

FIG. 10. As in Fig. 8, but during NO-TTA periods of (a),(b) 12-14 Jan 2003; (c),(d) 21-23 Jan 2003; (e),(f) 9 Jan 2004; (g),(h) 2 Feb 2004; and (i),(j) 16-18 Feb 2004. 

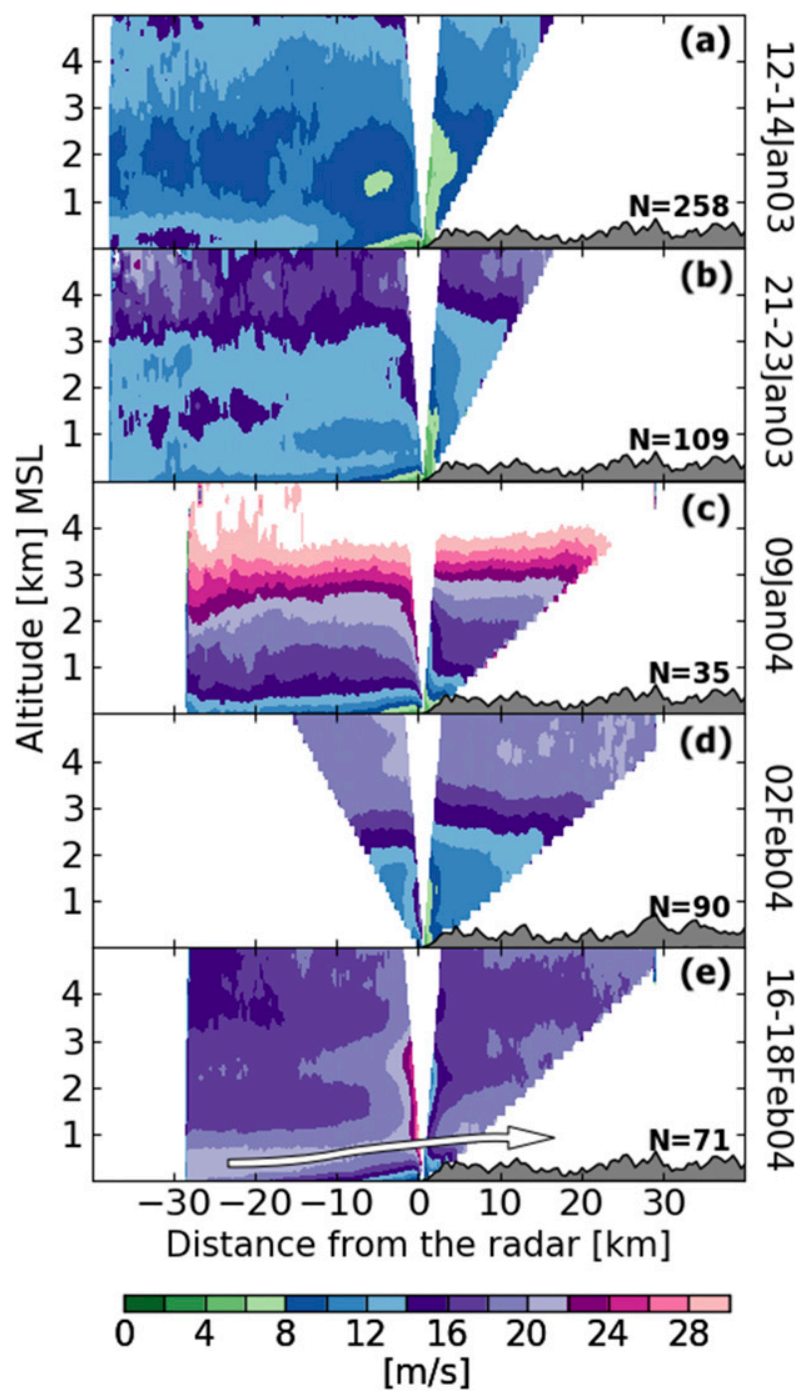

FIG. 11. As in Fig. 9, but during NO-TTA periods of (a) 12-14 Jan 2003, (b) 21-23 Jan 2003, (c) 9 Jan 2004, (d) 2 Feb 2004, and (e) 16-18 Feb 2004.

the NO-TTA regime, the random composite shows a similar increase of exceedance frequency onshore (Fig. 13b) compared to the corresponding seven-stormcomposite PPI (Fig. 7f). This comparison suggests that the seven-storm-composite structures presented in Fig. 7 are representative, except for the precipitation structure in the TTA regime. Also, the results of this analysis are consistent with the interstorm variability analysis in that precipitation structures exhibit comparatively larger variations during TTA conditions.

\section{e. Theoretical context}

The previous subsections documented kinematic and precipitation structures of TTAs, but their forcing mechanisms were not addressed. Two hypotheses that

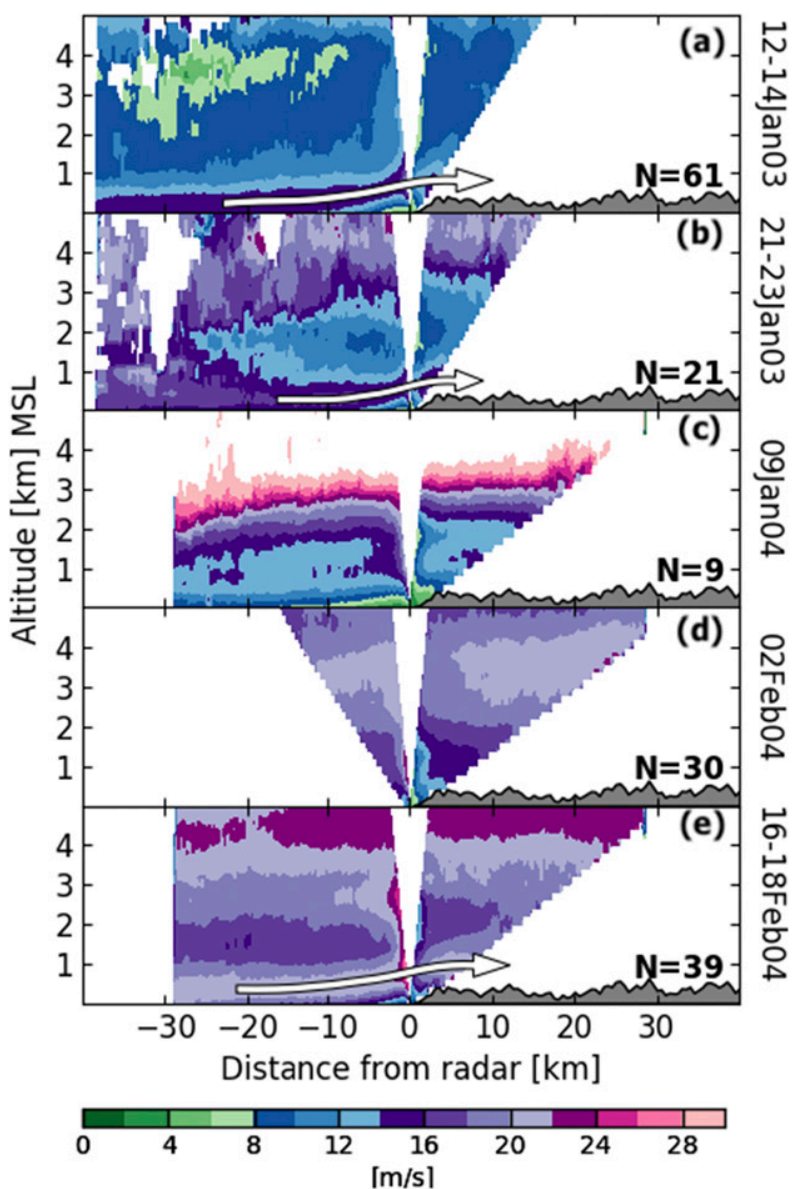

FIG. 12. Detail of the mean low-level jet (LLJ) structure during NO-TTA conditions on the (a) 12-14 Jan 2003, (b) 21-23 Jan 2003, (c) 9 Jan 2004, (d) 2 Feb 2004, and (e) 16-18 Feb 2004. Arrows indicate location of the low-level jet.

have been used to explain observed TTAs along midlatitude mountain barriers during wintertime are gap flow and low-level blocking. In this section, we discuss some details about these theories and attempt to apply them to the TTA periods of storms examined in this study (Fig. 4).

In a multiwinter analysis of gap flow episodes, Neiman et al. (2006) determined that the Petaluma Gap, whose exit is located at BBY (Fig. 1), has a significant influence on the local distribution of rainfall. Additionally, VK15 studied the 16-18 February 2004 storm in detail and concluded that a TTA was likely formed from a gap flow and created an enhanced precipitation zone offshore. The following discussion employs gap-flow theory as a theoretical framework to examine the forcing of each TTA observed. Hourly along-gap pressure difference is determined between BBY and a surface station located at Stockton, California (SCK; Fig. 1b). Zonal wind speed is derived at BBY from surface and layer-mean wind profiler observations between 0.1 and $0.5 \mathrm{~km}$ MSL (e.g., 
TTA

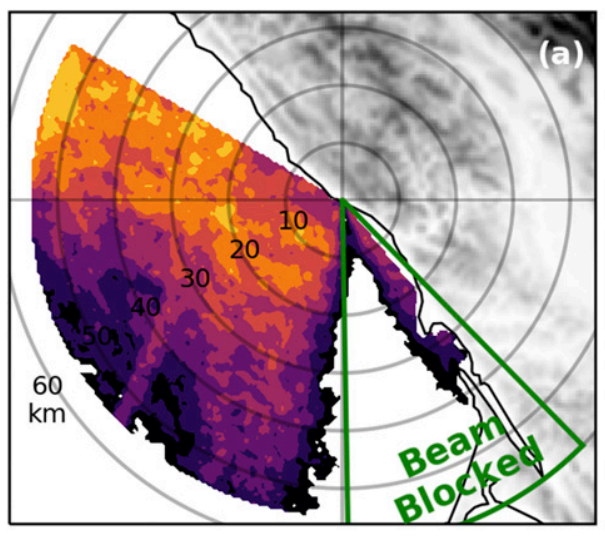

NO-TTA

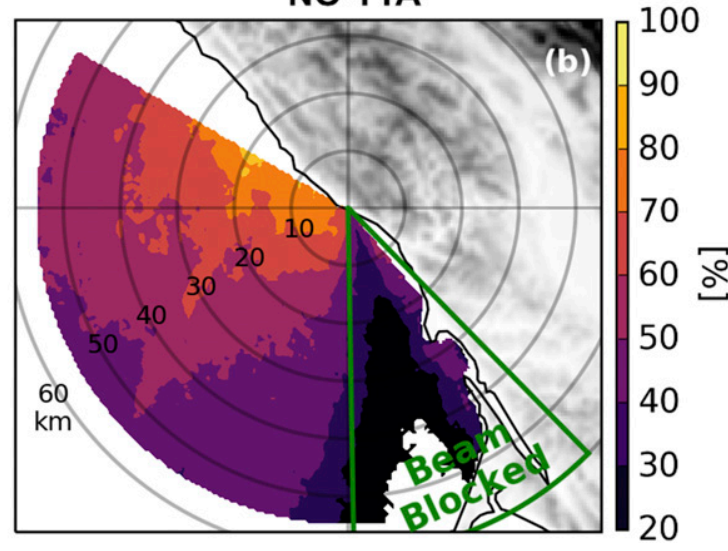

FIG. 13. Mean random composite for normalized frequency of exceeding threshold using horizontal attenuationcorrected reflectivity observations from X-Pol during (a) TTA and (b) NO-TTA conditions. Individual random composites are created using a random sampling with no replacement of each storm (Wilks 2011). The sample size in each storm corresponds to the smallest population of the group (e.g., the minimum number of sweeps), which in our case is determined by the 9 Jan 2003 storm (Fig. 6e). The median of the random sample was employed as the threshold to derive the normalized exceedance frequency. Vertical sections are meridionally oriented (i.e., azimuth $\left.0^{\circ}-180^{\circ}\right)$. Beam blockage by the radar trailer is indicated.

Neiman et al. 2006). These observations are examined using the analytical expression proposed by M95:

$$
u^{2}(x)=\left[u^{2}(0)-\frac{\mathrm{PGF}}{K}\right] e^{-2 K x}+\frac{\mathrm{PGF}}{K},
$$

where $u(0)$ and $u(x)$ represent the airflow at the entrance and at some distance $x$ downstream of the gap entrance, respectively; PGF is the along-gap pressure gradient force $\left[-\left(\rho^{-1}\right) \delta P / \delta x\right]$; and $K=2.8 C_{D} / H$ is a parameter representing friction through a dimensionless drag coefficient $\left(C_{D}=7.5 \times 10^{-3}\right)$ and the average depth of the boundary layer within the gap $(H)$. An average value of $\rho=1.24 \mathrm{~kg} \mathrm{~m}^{-3}$ and a constant value $H$ equal to $0.5 \mathrm{~km}$ MSL are assumed, which are in close agreement with Neiman et al. (2006). An analysis of this expression using $\delta P=500 \mathrm{~Pa}$ (i.e., average value observed for the seven storms), $\delta x=100 \mathrm{~km}$ (i.e., Petaluma Gap distance), and a range of values for $u(0)$ between 1 and $10 \mathrm{~m} \mathrm{~s}^{-1}$, all produce $u(x)$ values of $\sim 9.7 \mathrm{~m} \mathrm{~s}^{-1}$, indicating that for a long along-gap distance (i.e., $100 \mathrm{~km}$ ) $u(0)$ does not impact the result of $u(x)$ and that the airflow at the gap exit is dominated by $\mathrm{PGF} / K$. In other words, the $u(0)$ term can be neglected.

The value of $C_{D}$ used by M95 and taken from Arya (1988) considers surfaces with moderate roughness (roughness length parameter $<0.1 \mathrm{~m})$, tall crops $(\sim 60 \mathrm{~cm}$ long), and a near-neutral atmospheric stratification near the surface. In the case of Petaluma Gap, surfaces are composed (in different proportions) of grassland, mixed hardwood, chaparral, water, and urban structures (e.g.,
Thorne et al. 2004; Fenn et al. 2010), which suggests a different $C_{D}$. In addition, the approach of a warm advection regime in each storm indicates a more stably stratified condition, adding uncertainty to the value used by M95. Since the value of $C_{D}$ can significantly affect the estimation of the gap flow $[u(x)]$, we evaluate the parameter space associated with frictional forces by employing a theoretical envelope around Arya's $C_{D}$ using a $\pm 50 \%$ of variation $\left(3.75 \times 10^{-3}\right.$ to $\left.11.25 \times 10^{-3}\right)$, which represents approximately the roughness of plains during daytime and over deciduous forest (Stull 1988).

The gap flow analysis of TTA periods for the 12-14 January and 21-23 January 2003 storms (Figs. 14a,b) suggest no evidence of gap flow since all points are outside of the theoretical envelope for gap-flow conditions. In contrast, data points for the 9 January, 2 February, and 16-18 February 2004 storms (Figs. 14c-e) are closer to or within the gap-flow theoretical envelope, suggesting that gap flows might be influencing the TTAs associated with those storms. With the uncertainties in specifying parameters such as $C_{D}$ and $H$ of Eq. (1), it is reasonable to expect some observed points to lie slightly outside of the theoretical envelope, even if the TTA is actually forced by a gap flow.

An alternative theory for explaining the existence of a TTA is low-level blocking. Theoretically, low-level blocking on the windward side of a two-dimensional and infinitely long mountain barrier occurs when the ratio between the cross-barrier wind component $U$ (e.g., kinetic energy) and the product of the buoyancy frequency $N$ and the mountain height $h$ (e.g., potential energy) is less than 1 , expressed by 

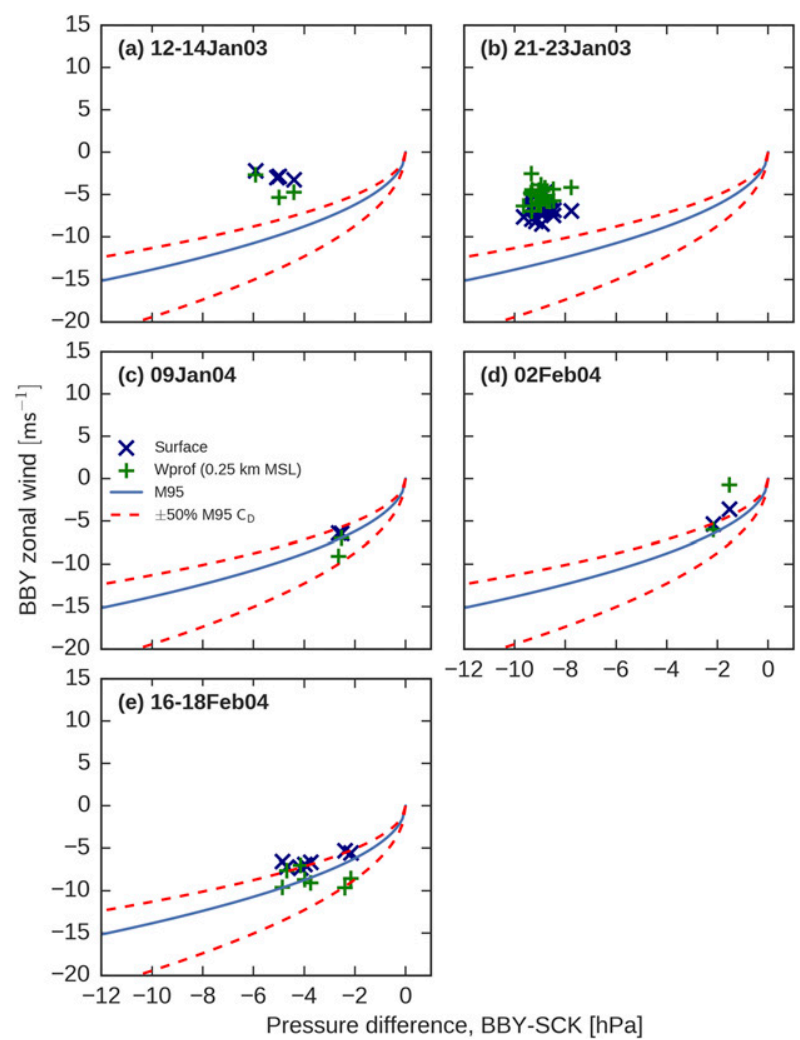

FIG. 14. Gap flow analysis using (Mass et al. 1995, hereafter M95) analytical expression for storms with TTA. Estimations at $(\times)$ and above $(+)$ the surface are included. Blue line uses same drag coefficient $\left(C_{D}\right)$ as in M95. Red dashed lines include a variation of (top) plus and (bottom) minus $50 \%$ of M95 $C_{D}$. A constant boundary layer altitude of $500 \mathrm{~m}$ is assumed. Each marker corresponds to time steps when surface and wind profiling observations are available at the same time (hourly resolution).

the Froude number (Fr, e.g., Smith 1979; Pierrehumbert and Wyman 1985):

$$
\operatorname{Fr}=\frac{U}{N h}
$$

The value of $N$ is usually represented by the BruntVäisälä frequency. If conditions are moist (i.e., observed relative humidity equal to or larger than $90 \%$ ), then the moist $N\left(N_{m}\right.$, Durran and Klemp 1982) is employed to account for the latent heat of condensation. The $N_{m}$ values are computed from balloon soundings launched at FRS. Since observations of $U$ (from $230^{\circ}$ ) along the coast would be biased by the presence of a TTA, average $U$ in the lowest $0.5-\mathrm{km}$ MSL and $1.0 \mathrm{~km} \mathrm{MSL}$ are derived upstream of the perturbed TTA airflow using X-Pol RHI and PPI observations. Winds in this layer are estimated at a range of $\sim 40 \mathrm{~km}$ from FRS. This location provides an estimate of wind conditions upwind (i.e., to the south) of the LLJ-TTA interface (e.g., our Fig. 8 and in detail in
VK15), which is presumably also the offshore extent of stable air associated with the TTA. RHIs of $180^{\circ}$ azimuth allows derivation of the mean meridional flow, while a nearly coincident X-Pol PPI scan at $0.5^{\circ}$-elevation angle provides an estimate of low-level wind direction to facilitate the calculation of $\mathrm{U}$ from the RHI scan.

Only the 21-23 January 2003 and 16-18 February 2004 storms had simultaneous X-Pol and balloon-sounding observations during the TTA period and therefore they are employed in the low-level blocking analysis (Fig. 15). The term $N_{m}$ is derived for two layers: the lowest $0.5 \mathrm{~km}$ MSL and $1.0 \mathrm{~km}$ MSL. The median values in each layer are used for the analysis (results hold the same when using mean values). It is evident that all points are in unblocked space relative to $h=0.5 \mathrm{~km}$ but results are mixed for $h=1.0 \mathrm{~km}$. For instance, 3 (2) points for the 21-23 January 2003 storm are in blocked (unblocked) space, whereas the only point for the 16-18 February 2004 storm is in unblocked space. Despite the fact that $\mathrm{Fr}=1$ is not a strict limit for defining blocking conditions in real threedimensional mountain barriers (e.g., Smith 1989), this result might suggest that a mountain height of $1.0 \mathrm{~km}$ could be influencing the dynamics along the coast.

The Rossby radius of deformation $\left(L_{r}=N_{m} h / f\right)$ represents the theoretical upstream extent of low-level blocking for a given barrier. Assuming $h=1.0 \mathrm{~km}, N_{m}=0.01 \mathrm{~s}^{-1}$ (e.g., an average of three blocked points during 21-23 January 2003), and $f=1 \times 10^{-4} \mathrm{~s}^{-1}$, then $L_{r}=100 \mathrm{~km}$. Mountain heights of $\sim 1.0 \mathrm{~km}$ are located $\sim 50 \mathrm{~km}$ inland from the coast. Then, a TTA with offshore extension of $\sim 40 \mathrm{~km}$ would be consistent with $L_{r}=100 \mathrm{~km}$ for a lowlevel blocked airflow induced by the inland mountains. As a consequence, $\mathrm{Fr}$ analysis suggests that at least some part of the TTA observed during 21-23 January 2003 might be forced by inland orography $(\sim 1.0-\mathrm{km}$ altitude) rather than coastal orography $(\sim 0.5-\mathrm{km}$ altitude) through lowlevel blocking. This result is consistent with Loescher et al. (2006), whose findings show a TTA influenced by terrain features as much as $100 \mathrm{~km}$ inland.

The theoretical analysis is also affected by sampling limitations, preventing the derivation of more robust conclusions. Compared with NO-TTAs, the duration of TTAs is shorter and thus the sampling size of these conditions is generally reduced. For example, in the gap flow analysis we find only a couple of points for the 9 January 2004 and 2 February 2004 storms since the wind profiler observations employed in the analysis has an hourly resolution. Even though these few points are near or within the theoretical envelop it is fair to ask how representative they are. Similarly, the testing of the low-level blocking hypothesis is affected by few sounding observations (none in some storms) during the TTA period. Despite these sampling limitations, 


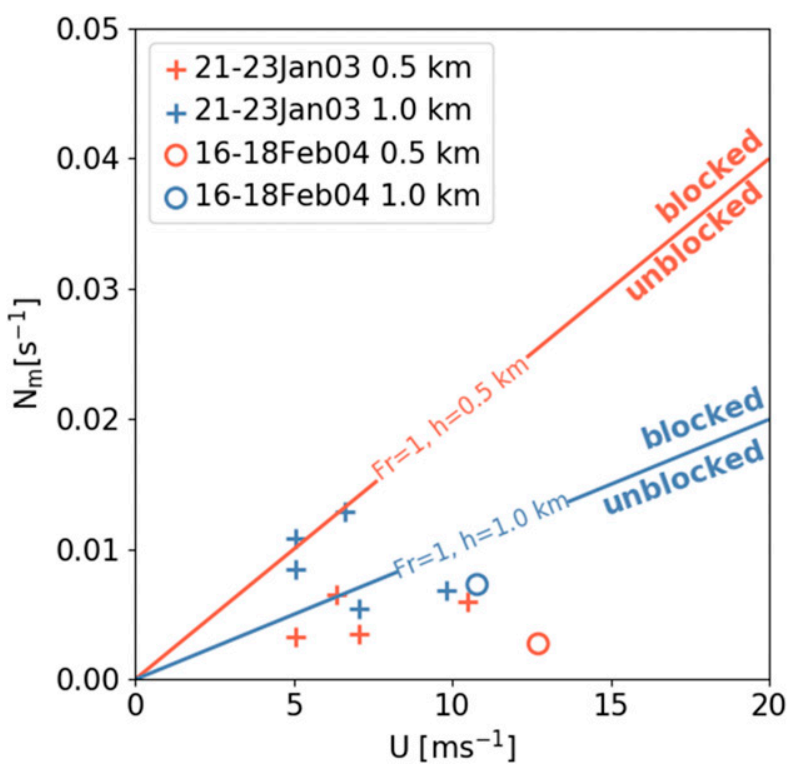

FIG. 15. Nondimensional Froude number analysis. Continuous lines indicate $\mathrm{Fr}=1$ for a mountain altitude $h$ of 0.5 and $1.0 \mathrm{~km}$. Annotation for blocked and unblocked areas relative to each altitude is indicated. Cases of 21-23 Jan 2003 (+) and 16-18 Feb 2004 (o) are included. Each marker corresponds to time steps when sounding and X-Pol radial velocity observations are available at the same time determined by the balloon sounding availability.

our results are providing some observational evidence of the forcing mechanisms of TTAs.

\section{Summary and conclusions}

This study has documented the mean properties and variability of TTA kinematic and precipitation structures associated with orographic precipitation observed along the coast of Northern California. Seven land-falling winter storms were examined with reflectivity and radial velocity data from a scanning X-band Doppler radar. Additional information was provided by a $915-\mathrm{MHz}$ wind-profiling radar, surface meteorology sensors, a GPS receiver, and balloon soundings.

The seven-storm composite analysis of TTA conditions revealed an average kinematic structure characterized by a significant horizontal gradient of wind direction with southeasterly winds along the coast transitioning to south-southwesterly at a range of $\sim 50 \mathrm{~km}$ from the coast. In the vertical, mean TTA kinematic structure indicated a low-level jet (LLJ) of $\sim 20 \mathrm{~m} \mathrm{~s}^{-1}$ surmounting a weaker airflow of $\sim 10 \mathrm{~m} \mathrm{~s}^{-1}$ corresponding to the TTA. The LLJ center was displaced upward by the TTA from $\sim 0.5$ (offshore) to $\sim 1.0 \mathrm{~km}$ MSL (at the coast). Mean horizontal precipitation structure showed an enhanced precipitation zone between $\sim 5$ and $25 \mathrm{~km}$ offshore and oriented roughly parallel to the coastline.
In contrast, seven-storm composite analysis of NOTTA conditions indicated an average kinematic structure characterized by southerly winds and only a small amount of directional shear in the horizontal. Precipitation enhancement during NO-TTA conditions was restricted to a zone within $\sim 15 \mathrm{~km}$ from the coast. LLJ structures were not readily apparent in either the horizontal or vertical analyses because the NO-TTA composite was associated with a relatively large fraction of X-Pol observation time compared with the total LLJ duration. Therefore, LLJ structures that are present during NO-TTA conditions were smoothed out by the longer NO-TTA sampling period, including times after the baroclinic wave passage. A random sampling procedure indicated that these composited structures were all representative of the storms sampled, except for precipitation structures during the TTA regime that showed large variations. Further research is needed to determine the extent to which these spatial patterns are representative of TTA and NO-TTA periods in general.

Interstorm variability analysis revealed relatively small deviations in the TTA kinematic structure in the horizontal but significant differences in the vertical plane, especially associated with storm-to-storm differences in LLJ magnitude of $\sim 10 \mathrm{~m} \mathrm{~s}^{-1}$ likely associated with synoptic forcing. The TTA precipitation structure observed during the 16-18 February 2004 storm consisting of an enhanced precipitation zone offshore $(\sim 30-\mathrm{km}$ range) oriented nearly parallel to the coast (also documented in VK15), is similar to the 2 February 2004 storm. There is some similarity with the 21-23 January 2003 storm but the enhanced precipitation zone is centered $\sim 25 \mathrm{~km}$ offshore and less elongated. Interstorm variability in the NO-TTA kinematic structure revealed relatively large variations in the zero-isodop shape and onshore wind magnitude. In most of the storms NO-TTA precipitation structures were characterized by an enhanced precipitation zone within $\sim 10 \mathrm{~km}$ of the coast. Since there is a gap in radar coverage just offshore and northwest of the radar, it is not possible to determine if these precipitation enhancements are also confined to similar offshore extents northwest of the radar and along the coast. Examination and comparison of LLJ vertical structures during TTA and redefined NO-TTA/LLJ conditions (including periods with LLJ structures as identified with the BBY wind profiler) revealed that LLJs tend to show an ascent offshore (along the coast) over the TTA (coastal mountains) during TTA (NO-TTA) conditions. The TTA identification method described in Part I of the present study seems to show issues in the NO-TTA classification of the 21-23 January storm, allowing the classification of a small-scale TTA near the radar as a NO-TTA feature. 
The analysis of storm-to-storm variability anecdotally suggested that only two storms were the dominant contributors in determining the structures observed in the seven-storm composites. To assess the representativeness of these composite structures, a random sampling without replacement was performed to derive mean random composites. The comparison between the seven-storm and mean random composites suggests that the sevenstorm-composite structures are representative, except for the precipitation structure in the TTA regime, which shows a random composite of less organized structure and lower frequency of enhanced precipitation offshore. Also, the results of this analysis are consistent with the interstorm variability analysis in that precipitation structures exhibit comparatively larger variations during TTA conditions relative to NO-TTA conditions.

Applications of gap flow and low-level blocking theory were employed to better understand the forcing mechanisms of TTAs. Results suggest that TTAs observed during 9 January, 2 February, and 16-18 February 2004 are best explained by a gap flow forcing. In contrast, the TTA observed during 21-23 January 2003 is best explained by low-level blocking associated with $\sim 1.0 \mathrm{~km}$ MSL terrain located $\sim 50 \mathrm{~km}$ inland. The TTA forcing during the 12-14 January 2003 storm is ambiguous because of the limited observations that prevent an analysis of both theories. Given the limited observations associated with these analyses, the results are far from definitive. Future studies should provide more evidence to test the importance of each forcing mechanism associated with TTAs.

It is worth noting that low-level blocking and gap flow are two forcing mechanisms associated with TTAs along the coast of Northern California. Given certain atmospheric conditions, one might be more reasonable to explain the TTA formation and maintenance than the other. For example, in the absence of a nearby mountain gap or the presence of either weak along-gap pressure gradient or weak inland cold pool, low-level blocking might better explain TTA formation. Similarly, an initially neutral atmosphere upstream of a mountain range could become increasingly stable forced by cold air brought through a gap flow, in which case a gap flow could better explain the TTA formation.

Although the interstorm variability analysis indicates a consistent horizontal kinematic structure of sharp curvature in the zero isodop for TTA periods, precipitation structures presented significant differences during these periods. One explanation could be associated with the magnitude of upslope IVT. For example, assuming the presence of the same TTA structure, differences in the upslope component of IVT could produce different horizontal precipitation structures. Another explanation for the differences in horizontal precipitation structure may be related to variabilities in the microphysical processes (e.g., cold vs warm rain) involved in precipitation development. Similarly, differences in precipitation structure could be associated with different characteristics of transient synoptic and/or mesoscale features (e.g., frontal circulations, moist/dry layers, symmetric instability). Future studies should explore these issues.

Acknowledgments. The authors thank the NOAA/ ESRL observing systems team for deploying and operating the instrumentation whose data were employed in this study. Timothy Coleman of ESRL processed and quality controlled the wind profiler observations. The thorough comments and suggestions of Paul Neiman and one anonymous reviewer helped to enhance the quality of the original manuscript. RV thanks Rene Garreaud for methodological comments. RV was partially supported by the Fulbright Program, CONICYTChile, and CIRES. This research was sponsored by NSF under Grant AGS-1144271.

\section{REFERENCES}

Arya, S. P., 1988: Introduction to Micrometeorology. 1st ed. Academic Press, 307 pp.

Businger, S., and Coauthors, 1996: The promise of GPS in atmospheric monitoring. Bull. Amer. Meteor. Soc., 77, 5-18, https://doi.org/ 10.1175/1520-0477(1996)077<0005:TPOGIA > 2.0.CO;2.

Colle, B. A., Y. Lin, S. Medina, and B. F. Smull, 2008: Orographic modification of convection and flow kinematics by the Oregon coast range and Cascades during IMPROVE-2. Mon. Wea. Rev., 136, 3894-3916, https://doi.org/10.1175/ 2008MWR2369.1.

Doyle, J. D., 1997: The influence of mesoscale orography on a coastal jet and rainband. Mon. Wea. Rev., 125, 1465-1488, https://doi.org/ 10.1175/1520-0493(1997)125<1465:TIOMOO > 2.0.CO;2.

Durran, D. R., and J. B. Klemp, 1982: On the effects of moisture on the Brunt-Väisälä frequency. J. Atmos. Sci., 39, 2152-2158, https:// doi.org/10.1175/1520-0469(1982)039<2152:OTEOMO>2.0.CO;2.

Ecklund, W. L., D. A. Carter, and B. B. Balsley, 1988: A UHF wind profiler for the boundary layer: Brief description and initial results. J. Atmos. Oceanic Technol., 5, 432-441, https://doi.org/ 10.1175/1520-0426(1988)005<0432:AUWPFT>2.0.CO;2.

Fenn, M., and Coauthors, 2010: Nitrogen critical loads and management alternatives for $\mathrm{N}$-impacted ecosystems in California. J. Environ. Manage., 91, 2404-2423, https:// doi.org/10.1016/j.jenvman.2010.07.034.

Garreaud, R., M. Falvey, and A. Montecinos, 2016: Orographic precipitation in coastal southern Chile: Mean distribution, temporal variability, and linear contribution. J. Hydrometeor., 17, 1185-1202, https://doi.org/10.1175/JHM-D-15-0170.1.

Houze, R. A., C. N. James, and S. Medina, 2001: Radar observations of precipitation and airflow on the Mediterranean side of the Alps: Autumn 1998 and 1999. Quart. J. Roy. Meteor. Soc., 127, 2537-2558, https://doi.org/10.1002/qj.49712757804.

James, C. N., and R. A. Houze Jr., 2005: Modification of precipitation by coastal orography in storms crossing Northern California. Mon. Wea. Rev., 133, 3110-3131, https://doi.org/ 10.1175/MWR3019.1. 
Kingsmill, D. E., P. J. Neiman, B. J. Moore, M. Hughes, S. E. Yuter, and F. M. Ralph, 2013: Kinematic and thermodynamic structures of Sierra barrier jets and overrunning atmospheric rivers during a landfalling winter storm in Northern California. Mon. Wea. Rev., 141, 2015-2036, https://doi.org/10.1175/MWR-D-12-00277.1.

—, P. O. G. Persson, S. Haimov, and M. D. Shupe, 2016: Mountain waves and orographic precipitation in a northern Colorado winter storm. Quart. J. Roy. Meteor. Soc., 142, 836853, https://doi.org/10.1002/qj.2685.

Kirshbaum, D., and D. Durran, 2004: Factors governing cellular convection in orographic precipitation. J. Atmos. Sci., 61, 682698, https://doi.org/10.1175/1520-0469(2004)061<0682: FGCCIO $>2.0 . \mathrm{CO} ; 2$.

Loescher, K. A., G. S. Young, B. A. Colle, and N. S. Winstead, 2006: Climatology of barrier jets along the Alaskan coast. Part I: Spatial and temporal distributions. Mon. Wea. Rev., 134, 437-453, https://doi.org/10.1175/MWR3037.1.

Martner, B. E., K. A. Clark, S. Y. Matrosov, W. C. Campbell, and J. S. Gibson, 2001: NOAA/ETL's polarization-upgraded x-band "HYDRO" radar. Preprints, 30th Int. Conf. on Radar Meteorology, Munich, Germany, Amer. Meteor. Soc., 101-103.

Marwitz, J. D., 1983: The kinematics of orographic airflow during Sierra storms. J. Atmos. Sci., 40, 1218-1227, https://doi.org/ 10.1175/1520-0469(1983)040<1218:TKOOAD>2.0.CO;2.

Mass, C. F., S. Businger, M. D. Albright, and Z. A. Tucker, 1995: A windstorm in the lee of a gap in a coastal mountain barrier. Mon. Wea. Rev., 123, 315-331, https://doi.org/ 10.1175/1520-0493(1995)123<0315:AWITLO > 2.0.CO;2.

Matrosov, S. Y., D. E. Kingsmill, B. E. Martner, and F. M. Ralph, 2005: The utility of $\mathrm{x}$-band polarimetric radar for quantitative estimates of rainfall parameters. J. Hydrometeor., 6, 248-262, https://doi.org/10.1175/JHM424.1.

Medina, S., B. F. Smull, R. A. Houze Jr., and M. Steiner, 2005: Cross-barrier flow during orographic precipitation events: Results from MAP and IMPROVE. J. Atmos. Sci., 62, 35803598, https://doi.org/10.1175/JAS3554.1.

Neiman, P. J., F. M. Ralph, A. B. White, D. E. Kingsmill, and P. O. G. Persson, 2002: The statistical relationship between upslope flow and rainfall in California's coastal mountains: Observations during CALJET. Mon. Wea. Rev., 130, 1468-1492, https://doi.org/ 10.1175/1520-0493(2002)130<1468:TSRBUF>2.0.CO;2.

,,--- D. D. Parrish, J. S. Holloway, and D. L. Bartels, 2006: A multiwinter analysis of channeled flow through a prominent gap along the Northern California coast during CALJET and PACJET. Mon. Wea. Rev., 134, 1815-1841, https://doi.org/10.1175/MWR3148.1.

- — , G. A. Wick, Y.-H. Kuo, T.-K. Wee, Z. Ma, G. H. Taylor, and M. D. Dettinger, 2008: Diagnosis of an intense atmospheric river impacting the Pacific Northwest: Storm summary and offshore vertical structure observed with cosmic satellite retrievals. Mon. Wea. Rev., 136, 4398-4420, https:// doi.org/10.1175/2008MWR2550.1.

— , A. B. White, F. M. Ralph, D. J. Gottas, and S. I. Gutman, 2009: A water vapour flux tool for precipitation forecasting. Proc. Inst. Civil Eng. Water Manage., 162 (2), 83-94.

—_, E. M. Sukovich, F. M. Ralph, and M. Hughes, 2010: A seven-year wind profiler-based climatology of the windward barrier jet along California's Northern Sierra Nevada Mon. Wea. Rev., 138, 1206-1233, https://doi.org/10.1175/ 2009MWR3170.1.

Parish, T. R., 1982: Barrier winds along the Sierra Nevada Mountains. J. Appl. Meteor., 21, 925-930, https://doi.org/10.1175/ 1520-0450(1982)021<0925:BWATSN>2.0.CO;2.
Peterson, T. C., L. O. Grant, W. R. Cotton, and D. C. Rogers, 1991: The effect of decoupled low-level flow on winter orographic clouds and precipitation in the Yampa River Valley. J. Appl. Meteor., 30, 368-386, https://doi.org/10.1175/1520-0450(1991)030<0368: TEODLL $>2.0$. CO; 2 .

Pierrehumbert, R. T., and B. Wyman, 1985: Upstream effects of mesoscale mountains. J. Atmos. Sci., 42, 977-1003, https://doi.org/ 10.1175/1520-0469(1985)042<0977:UEOMM > 2.0.CO;2.

Ralph, F. M., P. J. Neiman, and G. A. Wick, 2004: Satellite and CALJET aircraft observations of atmospheric rivers over the eastern North Pacific Ocean during the winter of 1997/98. Mon. Wea. Rev., 132, 1721-1745, https://doi.org/10.1175/ 1520-0493(2004)132<1721:SACAOO > 2.0.CO;2.

,-- , and R. Rotunno, 2005: Dropsonde observations in lowlevel jets over the northeastern Pacific Ocean from CALJET1998 and PACJET-2001: Mean vertical-profile and atmosphericriver characteristics. Mon. Wea. Rev., 133, 889-910, https://doi.org/ 10.1175/MWR2896.1.

- — , G. A. Wick, S. I. Gutman, M. D. Dettinger, D. R. Cayan, and A. B. White, 2006: Flooding on California's Russian River: Role of atmospheric rivers. Geophys. Res. Lett., 33, L13801, https://doi.org/10.1029/2006GL026689. , and Coauthors, 2013: The emergence of weather-related test beds linking research and forecasting operations. Bull. Amer. Meteor. Soc., 94, 1187-1211, https://doi.org/10.1175/ BAMS-D-12-00080.1.

Saha, S., and Coauthors, 2010: The NCEP Climate Forecast System Reanalysis. Bull. Amer. Meteor. Soc., 91, 1015-1057, https:// doi.org/10.1175/2010BAMS3001.1.

Sinclair, M. R., D. S. Wratt, R. D. Henderson, and W. R. Gray, 1997: Factors affecting the distribution and spillover of precipitation in the Southern Alps of New Zealand-A case study. J. Appl. Meteor., 36, 428-442, https://doi.org/10.1175/ 1520-0450(1997)036<0428:FATDAS > 2.0.CO;2.

Smith, R. B., 1979: The influence of mountains on the atmosphere. Advances in Geophysics, Vol. 21, Academic Press, 87-230, https://doi.org/10.1016/S0065-2687(08)60262-9.

1989: Hydrostatic airflow over mountains. Advances in Geophysics, Vol. 31, 1-41, https://doi.org/10.1016/S0065-2687 (08)60052-7.

— , and I. Barstad, 2004: A linear theory of orographic precipitation. J. Atmos. Sci., 61, 1377-1391, https://doi.org/ 10.1175/1520-0469(2004)061<1377:ALTOOP>2.0.CO;2.

,-- , and L. Bonneau, 2005: Orographic precipitation and Oregon's climate transition. J. Atmos. Sci., 62, 177-191, https:// doi.org/10.1175/JAS-3376.1.

Stoelinga, M. T., R. E. Stewart, G. Thomson, and J. M. Thériault, 2013: Microphysical processes within winter orographic cloud and precipitation systems. Mountain Weather Research and Forecasting, F. K. Chow, S. F. J. D. Wekker, and B. J. Snyder, Eds., Springer, 345-408, https://doi.org/10.1007/ 978-94-007-4098-3_7.

Stull, R. B., 1988: An Introduction to Boundary Layer Meterology. 1st ed. Kluwer Academic, 666 pp.

Thorne, J. H., J. A. Kennedy, J. F. Quinn, M. McCoy, T. Keeler-Wolf, and J. Menke, 2004: A vegetation map of Napa County using the manual of California vegetation classification and its comparison to other digital vegetation maps. Madrono, 51 (4), 343-363.

Trapp, R. J., and C. A. Doswell, 2000: Radar data objective analysis. J. Atmos. Oceanic Technol., 17, 105-120, https://doi.org/ 10.1175/1520-0426(2000)017<0105:RDOA > 2.0.CO;2.

Valenzuela, R. A., and D. E. Kingsmill, 2015: Orographic precipitation forcing along the coast of Northern California 
during a landfalling winter storm. Mon. Wea. Rev., 143, 35703590, https://doi.org/10.1175/MWR-D-14-00365.1.

, and $\longrightarrow$, 2017: Terrain-trapped airflows and orographic rainfall along the coast of Northern California. Part I: Kinematic characterization using a wind profiling radar. Mon. Wea. Rev., 145, 2993-3008, https://doi.org/10.1175/MWR-D-16-0484.1.

Weber, B. L., D. B. Wuertz, D. C. Welsh, and R. McPeek, 1993: Quality controls for profiler measurements of winds and RASS temperatures. J. Atmos. Oceanic Technol., 10, 452-464, https://doi.org/ 10.1175/1520-0426(1993)010<0452:QCFPMO>2.0.CO;2.

Wilks, D. S., 2011: Statistical Methods in the Atmospheric Sciences. 3rd ed. Elsevier, 676 pp.

Wolfe, D. E., and S. I. Gutman, 2000: Developing an operational, surface-based, GPS, water vapor observing system for NOAA: Network design and results. J. Atmos. Oceanic Technol., 17, 426-440, https://doi.org/10.1175/1520-0426(2000)017<0426: DAOSBG $>2.0 . \mathrm{CO} ; 2$.
Yu, C.-K., and B. F. Smull, 2000: Airborne Doppler observations of a landfalling cold front upstream of steep coastal orography. Mon. Wea. Rev., 128, 1577-1603, https://doi.org/ 10.1175/1520-0493(2000)128<1577:ADOOAL > 2.0.CO;2.

— , and Y.-H. Hsieh, 2009: Formation of the convective lines off the mountainous coast of Southeastern Taiwan: A case study of 3 January 2004. Mon. Wea. Rev., 137, 3072-3091, https://doi.org/ 10.1175/2009MWR2867.1.

Yuter, S. E., D. A. Stark, J. A. Crouch, M. J. Payne, and B. A. Colle, 2011: The impact of varying environmental conditions on the spatial and temporal patterns of orographic precipitation over the Pacific Northwest near Portland, Oregon. J. Hydrometeor., 12, 329-351, https://doi.org/ 10.1175/2010JHM1239.1.

Zhu, Y., and R. E. Newell, 1994: Atmospheric rivers and bombs. Geophys. Res. Lett., 21, 1999-2002, https://doi.org/10.1029/ 94GL01710. 